\title{
150 Years of Chemistry at the University of Zurich"\#
}

\author{
Conrad Hans Eugster
}

\begin{abstract}
This article was published in Chimia 1983,37, to commemorate the 150-year anniversary of Chemistry at the University of Zurich. This excellent historical account displays a depth of information and research that makes it very worthwhile reproducing here. It presents an account of Chemistry at the University of Zurich up to 1983 and has not been changed or updated in any way except translation into English from the original German.
\end{abstract}

Keywords: Chemical Institutes UZH · Karrer, P. · Werner, A.

\section{Introduction}

Medicine and the sciences were important subjects in the town of Zurich long before the University was founded. Names like Konrad Gessner, Josias Simmler, Johannes von Muralt, Johann Jakob Scheuchzer, Johannes Gessner or Salomon Schinz were known far beyond the confines of the town. The 'Naturforschende Gesellschaft Zürich' (Zurich Society for the Natural Sciences), founded in 1746, also had a significant influence in disseminating scientific concepts and reasoning. With the new Education

${ }^{*}$ Correspondence: Prof. C. H. Eugster

Institute of Organic Chemistry

University of Zurich

Winterthurerstr. 190

$\mathrm{CH}-8057$ Zurich

\# Translated by Dr. G. Harvey

CHIMIA Technische Redaktion

Pestalozzistr. 34

$\mathrm{CH}-8032$ Zurich

E-mail: chimia.tr@bluewin.ch
Laws passed in 28th September 1832, created and promoted by liberal political forces, long years of planning for the establishment of a University finally came to fruition. On 29th April 1833 the University was ceremoniously inaugurated with 159 matriculated students. The first vice-chancellor was Lorenz Oken, Professor for 'General Natural History, Natural Philosophy and Human Physiology'. With this choice, the Erziehungsrat (Cantonal Education Authority) placed a stronger emphasis on the sciences than was apparent at the (much older) University of Basel or - one year later - the University of Bern. This was particularly obvious in the weighting that chemistry received in the new curriculum from the very beginning: a Chair specifically for chemistry was created whereas the teaching of astronomy, botany, mathematics, mechanics, mineralogy, physics, zoology and geography (in the second semester) was done by senior lecturers (Privatdozenten). The new chemistry professor was also provided with a laboratory in the 'Carolinum' (Fig. 1) ${ }^{[1]}$ and a small annual budget for equipment, and after a short time he was even given a laboratory technician. It was fortunate the first occupant of the Chair in Chemistry was a chemist who not only taught but also undertook experimental research which enabled a flourishing school to develop.

\section{Early Times and the First Highlights: The Carolinum and Rämistrasse 59; Professors Löwig, Schweizer, Städeler and Wislicenus}

The first occupant of the Chair in Chemistry was Carl Jacob Löwig (Fig. 2), who was 30 at the time. He was originally a pharma- cist, but had been awarded his doctorate in chemistry in 1825 with Gmelin in Heidelberg. He subsequently assisted Mitscherlich in Berlin and then completed his habilitation at the University of Heidelberg in 1830 with his work on bromine which gained wide attention. ${ }^{[2]}$ In Zurich he quickly attracted many students. It was reported that he lectured very clearly, freely and almost elegantly. ${ }^{[3]}$ His experiments succeeded excellently. Löwig's also lectured on pharmaceutical chemistry and acted as an auditor in this subject for the Zurich apothecaries. He soon became more widely known in scientific circles as a successful author of textbooks. ${ }^{[4]}$ Löwig obliging nature made him many friends, especially in the secondary schools and amongst his colleagues in the Faculty of Medicine. His research initially concerned analysis of local mineral waters, presumably due to the available instrumentation and his own scientific background. ${ }^{6}$ However he soon turned to organic and physiological problems after acquiring new improved laboratory equipment and certainly at the suggestion of colleagues at the Fac-

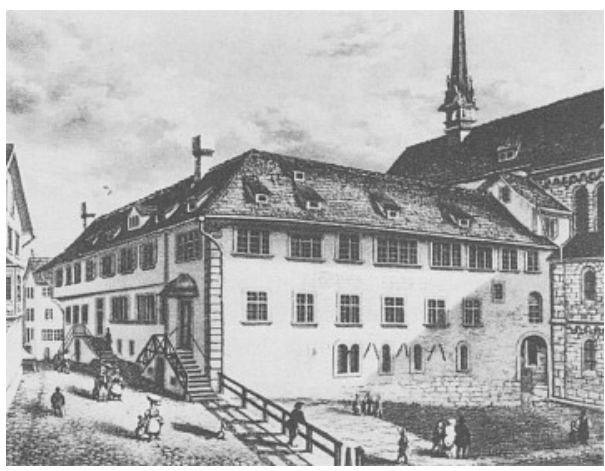

Fig. 1. The 'Carolinum' (Zwingliplatz to the front, back left Kirchgasse, back right Grossmünster) 


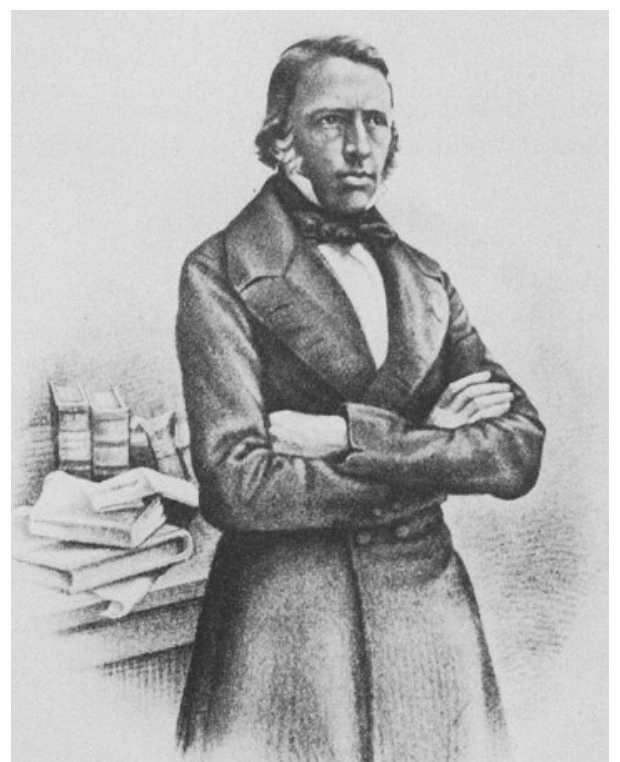

Fig. 2. Carl Jacob Löwig

ulty of Medicine (principally Schönlein and Kölliker). His discovery that cellulose made up the outer sheath of tunicates attrached wide interest. Until that time cellulose was considered as a typical plant material. More extensive investigations were devoted to the synthesis of aliphatic mercaptanes and sulfonic acids, mustard oils and novel reactions of antimony, lead and tin with alkylhalogenides. The latter reactions can be considered as highly significant from a historical viewpoint since, as we now know, Löwig was able to synthesize for the first time triethyl stibane, tetraethyl lead (!) and alkyl stannane and to characterize these as organometallic compounds. Löwig's method, the reaction of $\mathrm{Na} / \mathrm{Pb}$ - and $\mathrm{K} / \mathrm{Sb}$-alloys with ethyl iodide etc. is in principle still used today for the industrial synthesis of tetraethyl lead.

Löwig's success at teaching resulting in an increased number of students and soon made increases to the available space necessary. New laboratories were occupied in the 'Neue Kantonsschule'[7] (Fig. 3, Fig. 4) that had been built according to Löwig's design. At the time they were considered exemplary. They were used by Chemis-

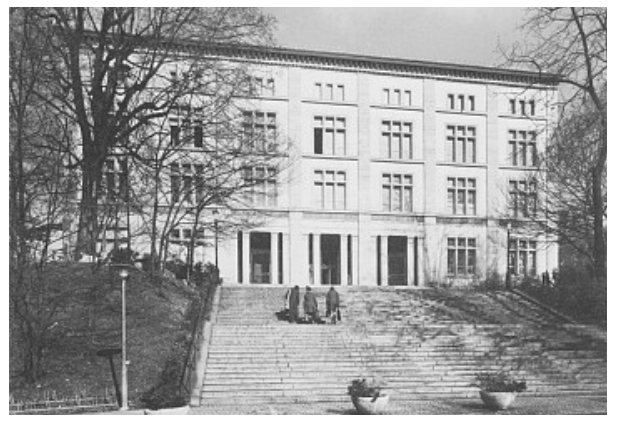

Fig. 3. Rämistrasse 59 (photo taken from the direction of Heimplatz)

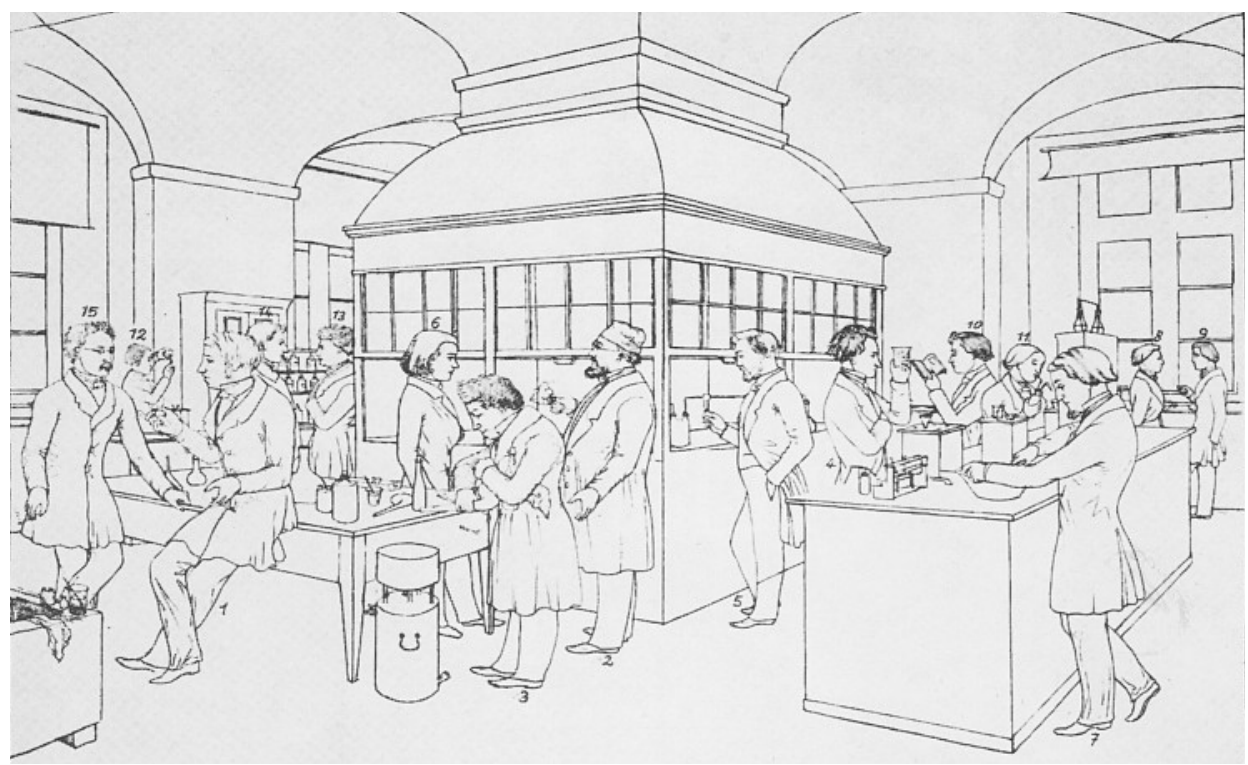

Fig. 4. Laboratory at Rämistrasse 59 (no. 1 C. J. Löwig, no. 2 M. E. Schweizer, no. 8, H. H. Landolt, no. 13 C. Heusser, from ref. [28]

try with certain improvements until 1887. Matthias Eduard Schweizer moved into the 'Kantonsschule' with Löwig. Previously in Germany he had trained in chemical technology and in metallurgy and mining. Where and when he completed his dissertation is not known. Schweizer was initially a lecturer at the Industrial School but completed his habilitation in chemistry and metallurgy in 1841. In 1852 the 'Regierungsrat' (the Cantonal government) promoted him to associate professor. Schweizer's most significant achievement was the discovery that cellulose could be dissolved in tetrammine copper solution (1857). The so-called Schweizer's reagent formed the basis much later for the industrial production of fibres from precipitated cellulose (cuprammonium silk or Kupferseide).

Löwig left Zurich in 1853 to take up a professorship at the University of Breslau as the successor to Robert Bunsen. He not only left a painful vacancy behind in $\mathrm{Zu}$ rich, even more significant was that he took his talented student Hans Heinrich Landolt with him. Landolt is recognized today as the founder of physical chemistry in Germany. His name lives on in the unique collection 'Landolt-Börnstein'. Löwig's new appointment confirmed the reputation that he had at that time. Despite this one cannot nowadays count him as one of the great chemists of his time. Löwig tolerated the limitations in Zurich and made the best out of them for himself and the University. He created the foundations for a successful development of the School of Chemistry. ${ }^{[3,8]}$

The successor to Löwig was Georg Städeler, a Wöhler student from Hannover. He had been working as an associate professor in Göttingen since 1851. In winter semester $1853 / 54$ he took up his position in Zurich. Originally the Erziehungsdirek- tion had hoped to attract Adolf Strecker, a talented student of Liebig's, to Zurich but this was unsuccessful.

The authorities were very farsighted in their appointment of Städeler: in teaching he showed great merit in introducing a systematic curriculum with written instructions for practical sessions ${ }^{[9]}$ and by productive research in organic chemistry. Subjects included amino acids, allantoin, creatine, chitin, fibroin, dyes from egg yolk etc. Städeler determined the correct empirical formula of lactose, xanthine, scyllitol etc. and synthesized pinacones from ketones by means of reduction with metal/acid.

When the 'Eidgenössische Polytechnische Schule' (Federal Polytechnical School $)^{[10]}$ opened on October 15, 1855, Städeler was named Professor of Theoretical Chemistry but also retained the title of Professor at the University.[11] $\mathrm{He}$ initially carried on using the laboratories in the 'Kantonsschule'. He moved into the chemistry building at Rämistrasse 45 (later 85) [12] in 1861, which had been built according Städeler's and Bolley's plans.[13]

The position of associate professor left vacant by death of Schweizer in 1860 remained unfilled for some time until the arrival of Johannes Wislicenus in 1864, who was only 29 at the time. This appointment allowed the University to take on a firstclass organic chemist. In his 12-year career as a chemist, Wislicenus had made a significant contribution to Kekülé's new and at the time revolutionary structure theory. ${ }^{[14]}$

After an eventful and difficult youth, Wislicenus completed his dissertation in 1860 under the supervision of Städeler. In the same year he made his habilitation in 'pure, applied and physical' chemistry at the University and the Polytechnic. ${ }^{[15]}$ After his appointment to associate professor and head 
of the chemistry laboratory at the 'Kantonsschule' (also known as University Laboratory II) Wislicenus began to lecture alternately on inorganic and organic chemistry. After his promotion (1867) the University had for a short time two full professors for chemistry although Städeler only lectured at the Polytechnic and announced his courses in the university course book. Under the leadership of Wislicenus the University Laboratory II developed to extraordinary levels, with experiments that no longer concentrated on physiological-chemical problems but rather the new structural chemistry. Despite the modest demands lack of space became ever more problematic. At the same time the activities of Städeler's group at the Polytechnic slowed, caused in part by Städeler's increasing chest and heart problems.

New rooms were found when the Laboratory for Veterinary Medicine and the 'Kantonsschule' moved into the chemistry building at Rämistrasse 45 (Fig. 5). Wislicenus declined the honour of a professorship at the University of Basel. His students celebrated his decision with a torchlight procession. When Städeler retired in 1870, Wislicenus became his successor.

He left the Kantonsschule and moved to the Rämistrasse. In 1871 the Bundesrat (the Swiss government) appointed him Director of the Polytechnic. Only one year later he
Fig. 5. Rämistrasse 45 (later 85; photo taken from Schmelzbergstrasse)

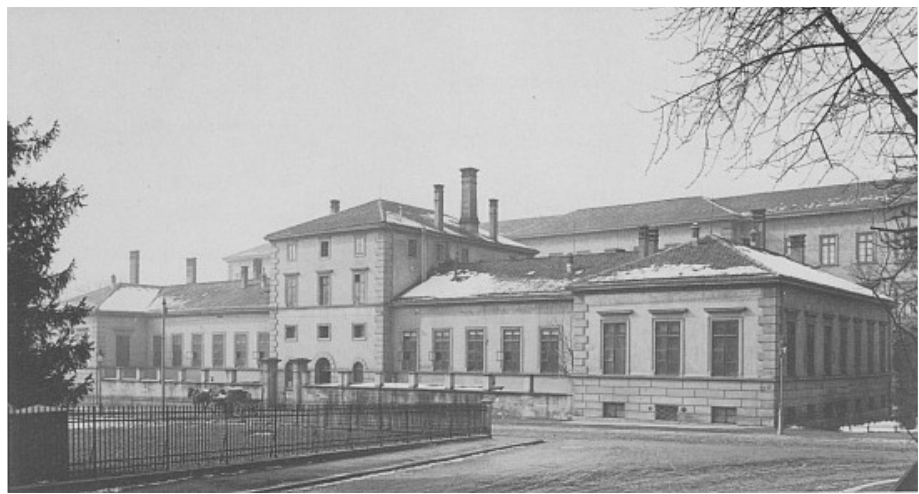

left Zurich and took up a position at the University of Würzburg. [16]

Many of the scientific achievements that Wislicenus produced in Zurich are today textbook knowledge, for example his work on the composition and synthesis of lactic acid and homologues and his momentous interpretation of the isomerization phenomenon of lactic acid of a 'different distribution of atoms in space'. Wislicenus' interpretation was the forerunner of the tetrahedron theory of Van't Hoff and Le Bel. His investigations on the 'origin of muscle force' that he undertook in collaboration with the physiologist A. Fick and the thermodynamic chemist R. Clausius in which they were able to show that sugar and fats were the energy carriers rather than proteins, received wide-spread recognition.

In Zurich Wislicenus founded the 'Chemische Harmonika', a scientific association for the discussion of new discoveries in chemistry. This was the immediate predecessor to the 'Zürcher Chemische Gesellschaft' (Zurich Chemical Society) which was founded in 1870 .

After Wislicenus' departure, the agreement between the University and the Polytechnic regarding a shared Chair in chemistry was discontinued. The chemistry lecturers had already left the laboratory on the Rämistrasse in 1870 and used the largely antiquated laboratories in the Kantonsschule until 1887 . The long-term interde-
Table 1. Full and associate professors of chemistry from Löwig to Karrer $(*$ shared professorship)

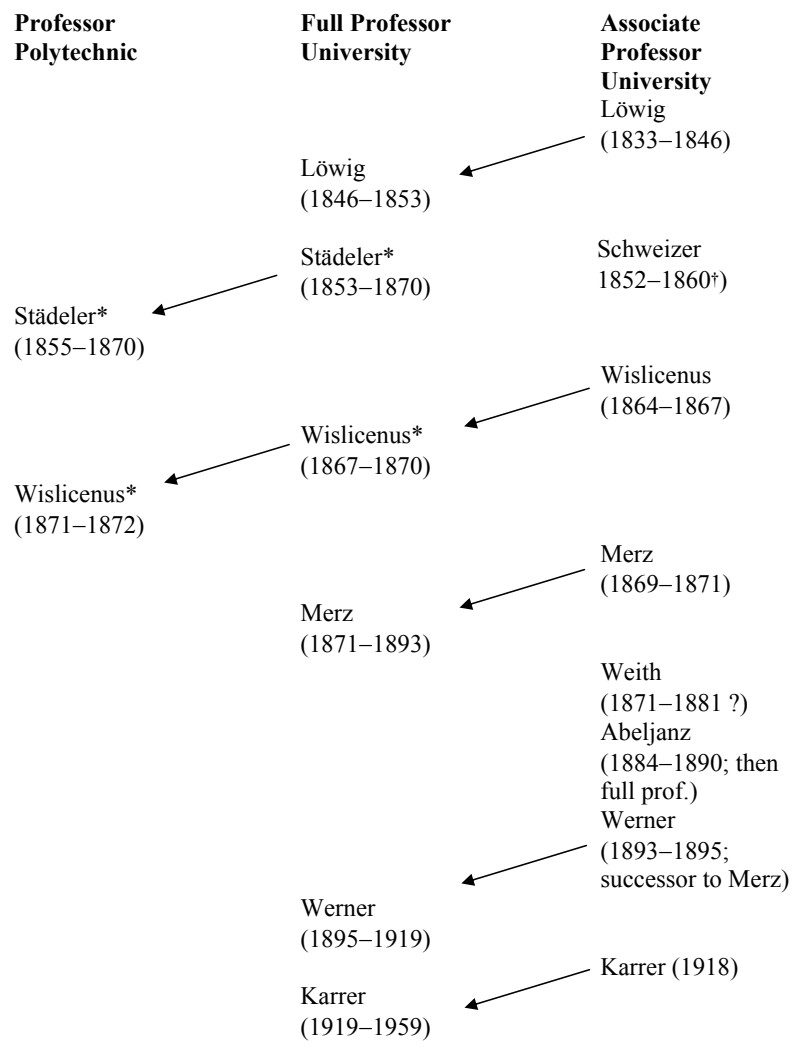

Table 2. The buildings occupied by Chemistry at the University

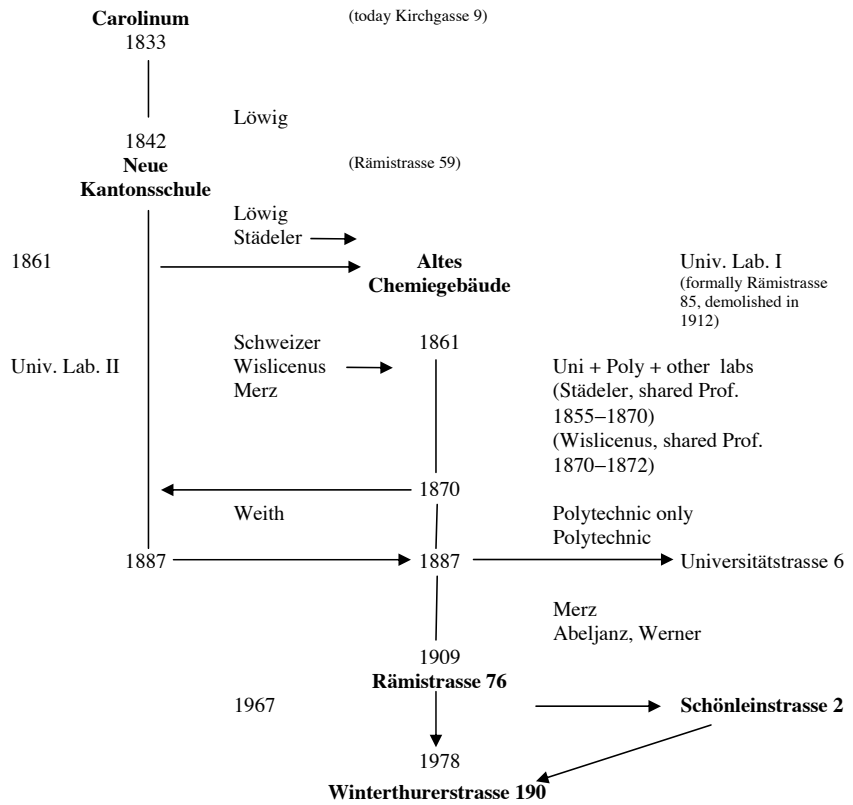


pendence of chemistry between the University and the Polytechnic had brought many disadvantages for the University. ${ }^{[6]}$ The complicated personal and accommodation relationships are shown in Tables 1 and 2 .

\section{The Team of Viktor Merz and Wilhelm Weith}

The names of these two chemists are no longer familiar to today's chemists; they are not commemorated by any 'named' reaction nor are they associated with any significant discovery. There are various and partly rather odd reasons for this that bear explanation. The reason that Merz and Weith merit a Section of their own here is partly due to the fact that they were able to attract a large number of students for chemistry and gave chemistry as a subject considerable weighting during a difficult time so that it was able to persist despite the glittering activities of Viktor Meyer, Wislicenus' successor at the Polytechnic. This was also despite the much more primitive working conditions that had to be endured compared to their colleagues at the purpose-built and well-equipped laboratories of the Polytechnic.

Viktor Merz ${ }^{[18]}$ (Fig. 6) was born in 1839 in Odessa, Russia, to Swiss parents originally from Appenzell. When he was 13 he was sent to Zurich to attend school. He is reported as saying that his teacher, Prof. Schweizer, inspired his interest in chemistry. He began his studies in chemistry at the Polytechnic with Städeler, but then transferred to the University in summer semester 1860. After studying in Munich with Liebig, he returned to Zurich to complete his dissertation in 1864 with Städeler. After his habilitation in 1866 he stopped work-

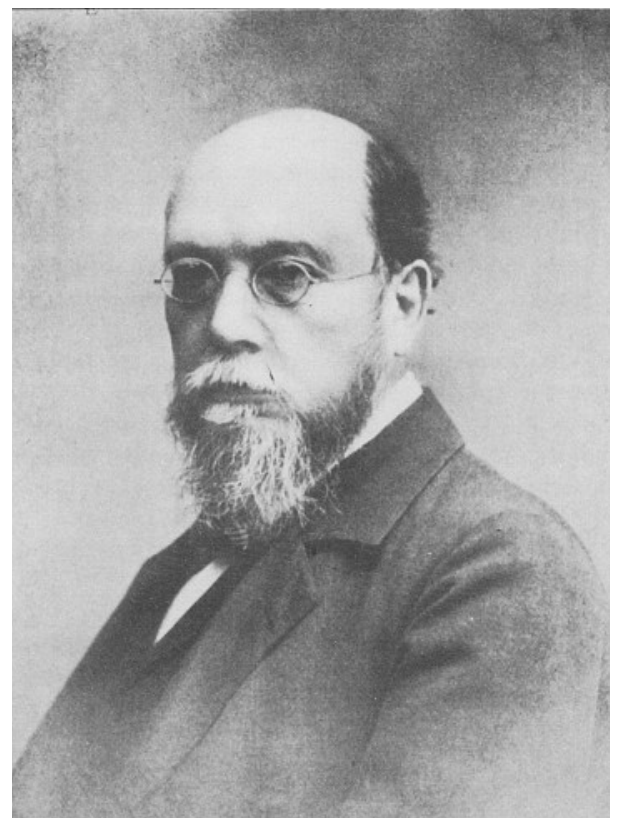

Fig. 6. Viktor Merz ing with Städeler after a disagreement and joined the group of Wislicenus at the University Laboratory II. During this time he got to know Weith, with whom he enjoyed a friendly and productive collaboration until Weith's death.

Weith, born in 1846 in Homburg (Prussia), also studied chemistry at the Polytechnic but then went to Bunsen in Heidelberg. In 1865 he completed his dissertation at the University of Zurich. Merz and Weith completed their habilitations at almost the same time at both the Polytechnic and the University. Their research was carried out at the University however. Merz was appointed as associate professor in 1869 and full professor and successor to Wislicenus in 1871 . At the same time Weith was appointed associate professor. During the appointment procedure to select Wislicenus' successor, the retention of the shared professorship at the University and Polytechnic was examined closely by the University Commission and at the same time the qualities of the two candidates were compared: Merz teaching style was less vigorous whereas Weith spoke more fluently and eloquently although without the scientific thoroughness of his colleague. The two men complemented each other excellently both in character and scientifically. ${ }^{[19]}$

This assessment was certainly shared by their contemporaries: Merz was described as tenacious, persevering and purposeful with a large capacity for work but also shy and taciturn whereas Weith was perceived as a lively, extravert blond northerner with an engaging character that won him many friends. Merz was only interested in chemistry whereas Weith also showed an interest in botany, geology, zoology and Swiss culture. He learnt the Zurich dialect easily; "He managed to find his way quickly through the unusual and for a foreigner, difficult to understand, political situation in Switzerland".[14]

The ascetic Merz often worked in the lab together with the physically weaker but stimulating and clever Weith until he (Weith) was overcome with complete exhaustion. After the early death of his friend, Merz became an increasingly withdrawn and lonely eccentric. ${ }^{[20]}$ In 1893 he retired

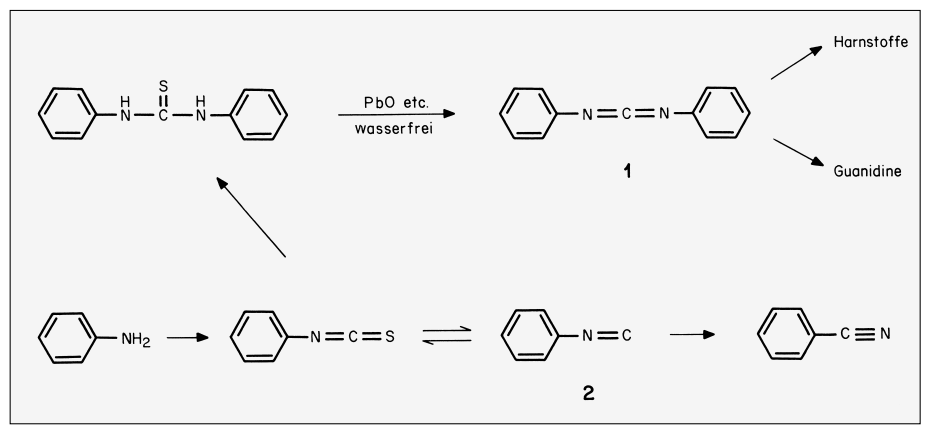

from his teaching position. Merz and Weith published many of their results together. The publications are characteristic of the time in which the main emphasis was on the discovery of new reactions, i.e. the transformation of functional groups. In Zurich the main interest was aromatic chemistry. As a reminder: in 1858 Peter Griess discovered the aryl diazonium salts, in 1865 Kekülé presented the formula of benzene and in 1866 Erlenmeyer that of naphthalene. In 1868 Caro and Graebe and Liebermann simultaneously synthesized alizarin.

Analysis of the publications of Merz yields a strange picture: 18 were written alone, 68 with Weith and other colleagues, whereas about 100 were written by him but published solely under the name of the respective student! It is for this reason that a large number of significant discoveries are not associated with the name of Merz (or Weith). ${ }^{[21]}$

Many syntheses were concerned with mustard oils and their derivatives in competition with the much more well-known A. W. Hofmann. Werz and Weith succeeded in 1879 with the first synthesis and at the same time the correct structure determination of diarylcarbodiimide (1) and they investigated many addition reactions of $\mathbf{1}$ with alcohols and amines. The isatine and indigo syntheses performed much later by $\mathrm{T}$. Sandmeyer (1899) relied on their research. The synthesis of isonitrile (2) from mustard oil followed by rearrangement into nitrile is a good example of the widely studied 'desulfurization' reaction (Scheme 1). For the first time it was possible to transform arylamines into aryl carboxylic acids.

Examination of the many publications and lecture reports from the Zurich 'University Laboratory' reveal a picture of empirical sampling of the reactivity of aromatic compounds with experimental conditions that are no longer used today. For example syntheses of unsymmetrical arylketones were performed by condensation of carboxylic acids with aromatic hydrocarbons and $\mathrm{P}_{2} \mathrm{O}_{5}$ in a sealed tube. Later, in 1873, Merz discovered that the reaction of carboxylic halides in the presence of metallic zinc proceeded with high yields. The more efficient catalyst, aluminium chloride, was not intro-
Scheme 1. Desulfurization reactions 
duced until 1877 by Friedel and Crafts and therefore this textbook reaction carries their names and not Merz'. Extensive substitution reactions were carried out on the readily accessible sulfonic acids and halides to introduce other functional groups leading to the discovery that perhalogenated aromatics easily underwent nucleophilic substitution of the hydroxyl group by phenols (e.g. 3 (Scheme 2)) and that in the naphthalene series amines occupy the position adjacent to the leaving group $(\mathbf{4} \rightarrow \mathbf{5})$.

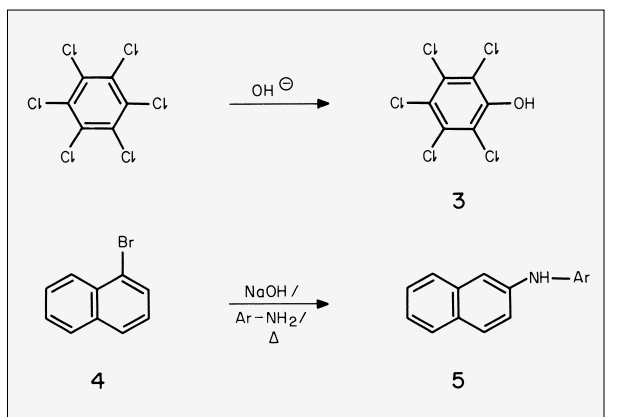

Scheme 2. Nucleophilic substitution of aromatics

This last reaction, which could not be interpreted at the time, was also not published by Merz but by his assistant O. Kym.

Diarylethers were synthesized for the first time from phenols; also the first synthesis of triphenyl amine from aniline and bromobenzene with potassium(!). Much effort was put into ring halogenations with $\mathrm{Cl}_{2} / \mathrm{SbCl}_{5}$. This resulted in the first synthesis of perchlorobiphenyl (PCB) (G. Ruoff, 1876); the widespread use of this compound for industrial purposes has led to serious environmental problems today. The transformation of phenols into arylamines with the help of tetraammine zinc salts was also perfected. The substitution of aromatics with elementary sulfur or sulfonyl chloride yielded diarylsulfide.

Weith was often ill and therefore forced to abandon his lab work, which however is not reflected in the number of publications. During a period of convalescence in Corsica in 1881 he died of a lung haemorrhage at the age of 35. ${ }^{[22]}$ Merz was deeply affected by the death of his friend. Despite this, many noteworthy results continued to be published, usually under the names of his students.

For example the first synthesis of phenazine (6) and 5-phenyl-oxazole (7) (Scheme 3 ) were performed; reactions that are well known in heterocyclic chemistry but, for the above-mentioned reasons, not associated with the name of Merz.

After completion of their studies nearly all of the numerous doctoral students of Merz and Weith took up positions in industry, reflecting their empirical and experimental training. Well-known names include
R. Bindschedler, founder of a chemical factory in Basel (predecessor to Ciba) and A. Bischler (later a director of Ciba).

In 1886 the Polytechnic chemists moved into their impressive new chemistry building on Universitätsstrasse 6, which in an extended form is still in use today. Its excellent practical design was achieved thanks to the planning of Georg Lunge and Victor Meyer. At the time the chemistry building on Rämistrasse 45 (and 85) became free. Instead of a new construction the authorities made do with a meagre renovation of the completely outdated building and moved in not only the Chemical Institute but also the Hygiene Laboratory, the Laboratory of the Cantonal Chemist, Pharmacology and the Kantonsschule(!). The institutes took up residence in 1887. The successor of Weith in 1884 was $\mathrm{H}$. Abeljanz who originated from Armenia. He had completed his dissertation under the supervision of Wislicenus in 1872, was the first Cantonal Chemist of the Canton of Zurich from 1877-1884 and produced much good work while in this office.[23]

\section{The Werner Era}

After the retirement of Merz in 1893, the 27-year old Alfred Werner (born 12.12.1866 Mulhouse, died 15.11.1919 Zurich) was named as his successor, initially as associate professor (in addition to Abeljanz, who was elected full professor in 1890). He began lecturing in winter semester 1893/94. He was promoted to full professor two years later. Werner had studied chemistry at the Polytechnic since the winter semester 1886/87 and completed his degree under the supervision of Lunge in technical chemistry in 1889. ${ }^{[24]}$ After working as an assistant to Lunge he completed his dissertation under the supervision of Hantzsch which he submitted to the University of Zurich and where he also undertook his doctorate exam. ${ }^{[25]}$ Hantzsch advised him to go to Marcellin Berthelot for one semester at the Collège de France in Paris. ${ }^{[26]}$

Upon his return Werner made his habilitation at the Polytechnic in chemistry and lectured for three semesters (summer semester 1892 - summer semester 1893) on 'Atom Theory', 'Selected Aspects of In- organic Chemistry', 'Comparative Organic Chemistry' and 'Stereochemistry'. It is obvious that Werner had an encyclopaedic knowledge of chemistry even during these early years. At the same time he gained the reputation of an excellent lecturer with great charisma. The election to associate professor was not without controversy. ${ }^{[27]}$

After the matter was settled in favour of Werner, he took over the Section A (chemists) whereas Abeljanz took over Section B (medical students, teaching candidates, food chemists). At first Werner was only permitted to lecture on basic organic chemistry. ${ }^{[30]}$ His lecture course was well constructed and he lectured with great conviction. The students rush to hear him! The 130-seat lecture theatre soon had to accommodate 200 to 250 students. "The students sat on the window sills and aisles, and crowded around the laboratory bench". ${ }^{28]}$ Only after intervention by the Faculty and a decree by the authorities was Werner permitted to take over the inorganic chemistry lecture course in 1902.[31]

For a long time Werner was in doubt whether to join the great enthusiasm for organic structural chemistry or whether he should turn his attention to the neglected confusing diversity that defined inorganic chemistry. In fact in addition to his investigations on the stereochemistry of oximes and hydrazone (see below) Werner had undertaken a great deal of research on phenanthrene and its substitution products, the Beckmann rearrangement (in connection with the structure determination of stereoisomeric oximes), the synthesis of hydrocarbons with $\mathrm{Mg}$ organyls and other typically organic chemistry projects. For example there was his discovery of the 'Beckmann rearrangement type II' which is classified today as the fragmentation of an oxime with the production of a nitrile. He resolved transcyclohexan-1,2-dicarboxylic acid into its enantiomers for the first time and demonstrated that the cis-isomer could not be resolved. Werner also regularly published reports on new discoveries in fields such as the alkaloids, sugars, organometallics, natural dyes and terpenes. It appears that Bischler was able to convince him after many discussions ${ }^{[28]}$ that he should con-

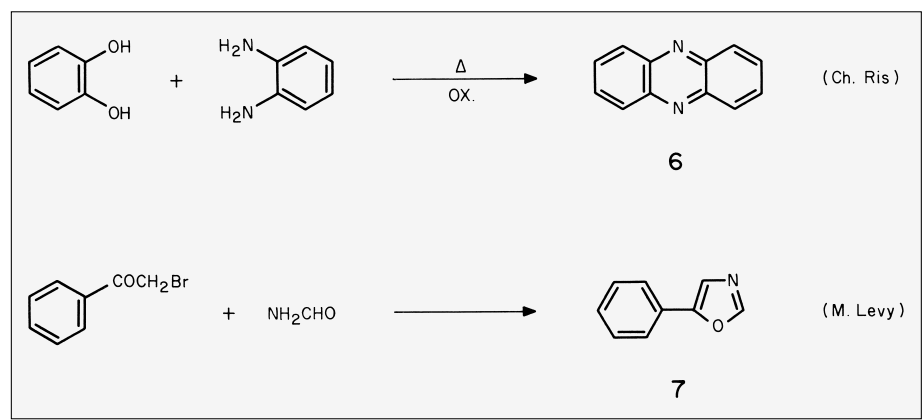




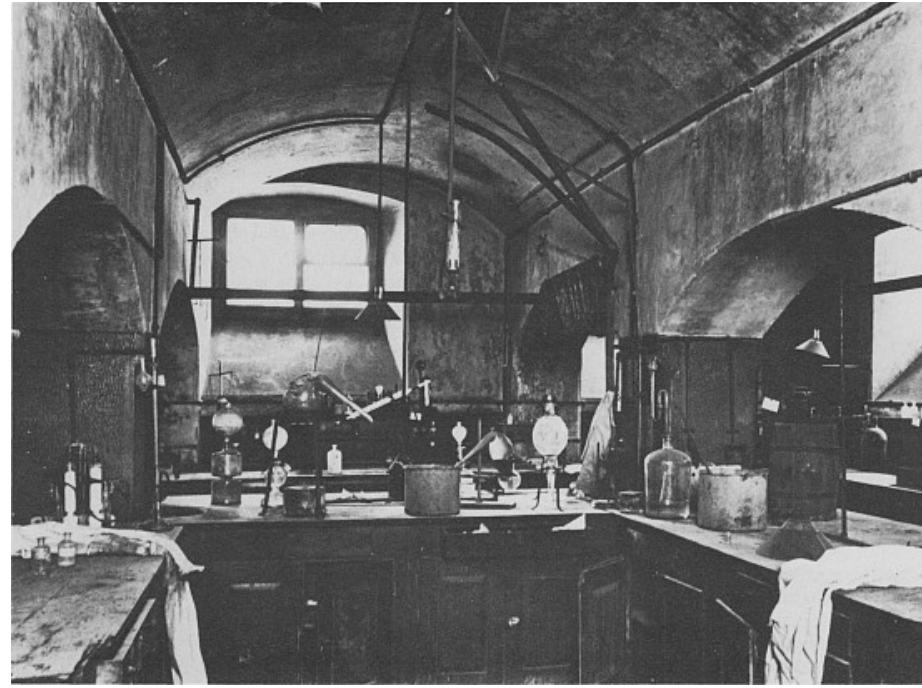

Fig. 7. Laboratories in the basement of Rämistrasse 45 (the catacombs)

centrate on inorganic chemistry. Publications on organic chemistry continued to appear occasionally up to 1900 , after that they ceased.

The conditions under which Werner's monumental research was performed were primitive (Fig. 7). Although it must be recognised that apart from correct mixing, skilful crystallisation and careful analysis, ${ }^{[32]}$ there were no exceptional experimental demands. As a result the workplace of a doctoral student was equipped simpler than that of a beginner today in a subsidiary practical course.

The large number of doctoral students and assistants meant that every corner of the institute had to be utilised: "Laboratory benches were installed in former cellars and wooden containers, in rooms in which there was insufficient daylight even on the sunniest day, making the use of artificial light unavoidable. There was no question of ventilation and the heating pipes carrying steam, installed at head height, contrasted rather unpleasantly with the cold cement floors that provided cooling." [6] The students named these rooms the 'catacombs'. That chemistry at the University flourished despite such dreadful conditions is thanks to the genius of Werner. One should recall the excellent equipment that the students at the Polytechnic were provided with and the generous capacity that the chemistry lecturers had access to. ${ }^{[33,34]}$

After many applications to the authorities, visits by commission members and in the face of the threat that Werner really intended to take up an offer from another university, ${ }^{[36]}$ the Regierungsrat decided to submit the plans for a new building to the Cantonal parliament, which was accepted on 25.6.1905 in a referendum with a very good result. The sum of 2,790,000 sFr, a very large amount for those days, was made up from various sources: $500,000 \mathrm{sFr}$. one-off payment from the town of Zurich, 225,000 sFr. book value for the land (transferred to non-realisable assets), $600,000 \mathrm{sFr}$. for a new building for the Cantonal Technical School in Winterthur, 65,000 sFr. for renovation and improvement of the former Kantonsschule building ${ }^{[37]}$ and 1,400,000 $\mathrm{sFr}$. for the construction of the new building at Rämistrasse 74 and 76 (Fig. 8). Due to delays in the construction work, the buildings were not accessible until summer semester 1909. The pride of the students and professors was immense. ${ }^{[29]}$ To commemorate the opening, some chemistry students, whose names are no longer known, prepared a document extensively describing the former working conditions. ${ }^{[6]}$

One peculiarity of the new building that had been designed entirely according to the wishes of Werner should be mentioned: Werner had direct access to all the rooms in his wing by means of connecting doors without having to use the corridor; to the small lecture theatre, the private laboratory, the microlab, the library and a room for doctoral students. In addition, by climbing small iron spiral staircases directly from his office, he came to the practical laboratory below or to the preparation room of the large lecture theatre on the floor above. Later, Karrer also made good use of these

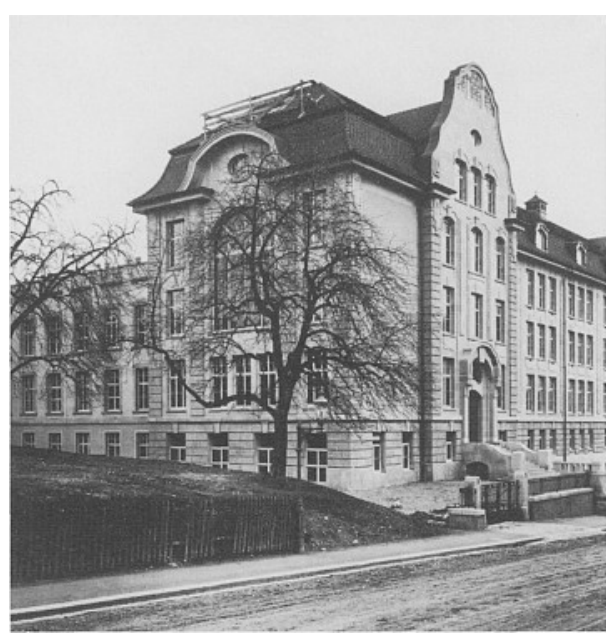

Fig. 8. Rämistrasse 76 staircases. They were only removed completely in the time of H. Schmid. ${ }^{[38]}$

\section{Werner as a Person ${ }^{[39]}$}

Werner (Fig. 9) was described by his biographers, particularly in his younger years, as cheerful and sociable and as someone who sought contact with similarly thinking people. From an early age he tended to put on weight. His straightforward character and his direct and blunt manner were also mentioned, which sometimes resulted in rejection in others of a different character. To most people he appeared, especially in his middle and later years, as a powerful, and intellectual, almost superhuman being with an unbelievable work ethic. Some were afraid of him, since he despised halfmeasures and was not easily prepared to compromise. But it is also clear from many accounts that he was honoured by most as a research scientist and teacher. The students called him 'der Alte' (the Boss). Werner can be described as a hard worker who followed his own objectives with unbelievable tenacity and always put work before personal matters.

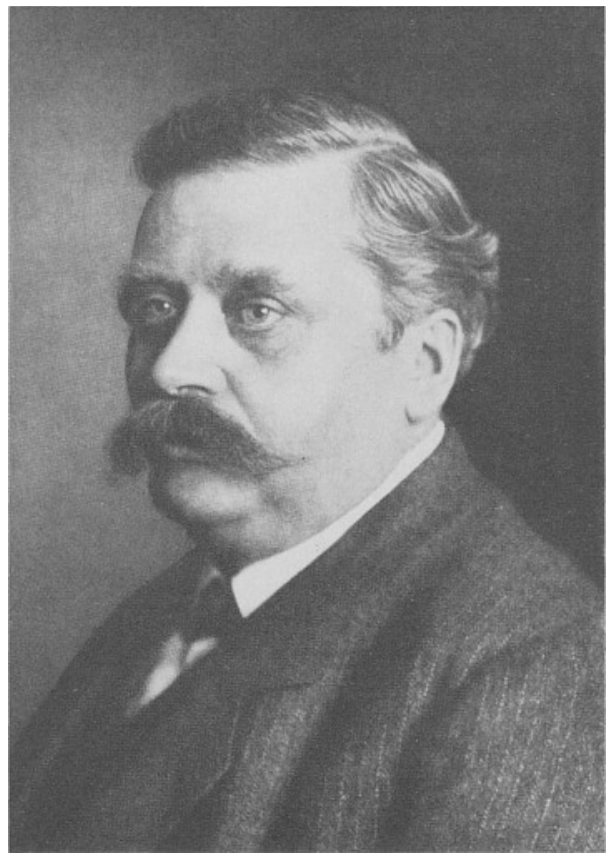

Fig. 9. Alfred Werner

Kauffmann ${ }^{[29]}$ named the following attributes in his analysis of Werner's complex personality, which naturally were more or less pronounced depending on the circumstances: high natural intelligence, sensitive, creative, intuitive, imaginative, ambitious, undaunted, impulsive to aggressive, egocentric. One could add: excellent three-dimensional visualisation, extraordinary memory, systematic working methods, Werner was said to be the first in the laboratory in the morning and 
usually the last to leave at night. He and his assistants also worked on Saturdays. Werner also spent Sunday mornings in the institute unless he went hunting in Canton Aargau with colleagues.

Werner was very attached to four scientific societies; he attended the society events regularly, in which he lectured himself and he served on their committees. The venerable 'Naturforschende Gesellschaft Zürich' (for which he served in various offices between 1894 and 1910), the 'Schweizerische Naturforschende Gesellschaft' (Swiss Society for Natural Sciences), the 'Zürcher Chemische Gesellschaft' (Zurich Chemical Society) and the 'Schweizerische Chemische Gesellschaft' (Swiss Chemical Society) (he was a founding member and its first president). His imposing figure with the ever-present cigar was a familiar sight at the meetings. He also helped to establish the society journal, the Helvetica Chimica Acta. The very first publication was from Werner himself.

In his early years Werner enjoyed sport. His physical strength enabled him to undertake strenuous hiking and mountaineering trips, he enjoyed bicycle riding, ice skating and rowing. He was a member of the 'Seeclub Zürich'. Another aspect to his character was his love of games. He was a passionate 'Jasser', he enjoyed bowling and billiards. For a time he concentrated on chess. He was a member and later honorary member of the Chess Society of Zurich. He also collected stamps and owned a valuable collection.

His fondness for good food and wine is generally well known. With increasing age he indulged increasingly in alcohol until he eventually became addicted. Apparently - but only apparently - the excessive alcohol had no influence on his strong body. The big parties that he celebrated with the chemists at Christmas or during institute outings have gone down in history. Kar- rer, his biographer, who knew Werner extremely well, remarked in his dry manner: "His exceptional qualities were innate: in his work, in the fulfilment of his duties and also in his social life."

His ability to supervise simultaneously a large number of doctoral students is wellknown (Fig. 10). During his daily rounds he was informed about every small detail. Many reports attest to his excellent experimental skills: On his laboratory bench were a microburner, microfilter, a platinum spatula, countless watch glasses, a porcelain plate and many reagents. He could perform ligand exchange reactions on the microscale perfectly and was able to conclude, according to the colour change, the nature of the new complex before the analysis results were available.

In his early years Werner organised discussion evenings on new issues in chemistry. They appear to have been difficult for the participants to follow due to the demanding level of understanding required and particularly because Werner preferred not to use the blackboard for explanations.

Werner became a Swiss citizen when he married (1.10.1894) Emma Wilhelmine Giesker (14.12.1872-15.4.1962). He loved this country and its democratic institutions. In 1898 he had a house built for his family at Freiestrasse 111, close to the institute. His son Alfred (22.7.1897-18.12.1954) became a doctor. His daughter Charlotte (16.4.1902-19.1.1980) donated the generous 'Alfred Werner Legacy' to the Chemical Institutes.

\section{Werner's Scientific Achievements ${ }^{[45]}$}

"Werner's coordination theory has been a guiding principle in inorganic chemistry and in the theory of valence since its publication sixty years ago. Indeed, it might have been said to underline our modern concepts of molecular structure. The current theories of acidity, basicity, amphoterism and hydrolysis grew directly from it, and..."[50]

"...in attempting to clarify the fundamental ideas of valence, there is no work to which I feel so much personal indebtedness as to this of Werner's" (G. N. Lewis ${ }^{[52]}$ ).

"Werner's work has, indeed, been of the greatest importance for the development of chemistry. It is remarkable that a man with only an elementary knowledge of mathematics and physics should have been able to discover the principles according to which atoms combine, especially during a time when it had become fashionable to doubt the very existence of atoms (Wilhelm Ostwald). It was Werner's remarkable ingenuity and powers of intuition that enabled him to deduce these principles from a study of chemical phenomena alone" (G. Schwarzenbach ${ }^{[48]}$ ).

In the following three areas of research have been selected to demonstrate the high regard for Werner evident in the above quotations; the pure organic chemistry research that has been mentioned above should not be underestimated.

\section{Oxime and Hydrazone Isomerism}

In his dissertation in 1890, Werner tackled the controversial subject of the structure of the isomeric oximes; see $[46,53,54]$ and the formulations of Meyer and Auwers (1888) (Scheme 4).

This comparison reveals the uncertainty that prevailed with respect to basic stereochemistry in the minds of the great chemists of the day and shows brilliantly the impartiality and genius of Werner's reasoning. Every new chemistry student is able after two semesters to determine the number of possible isomers without problem. It is no surprise therefore that Hantzsch' and Werner's formulation was not accepted unquestioningly[29] because the geometric reasoning of Werner was too novel.

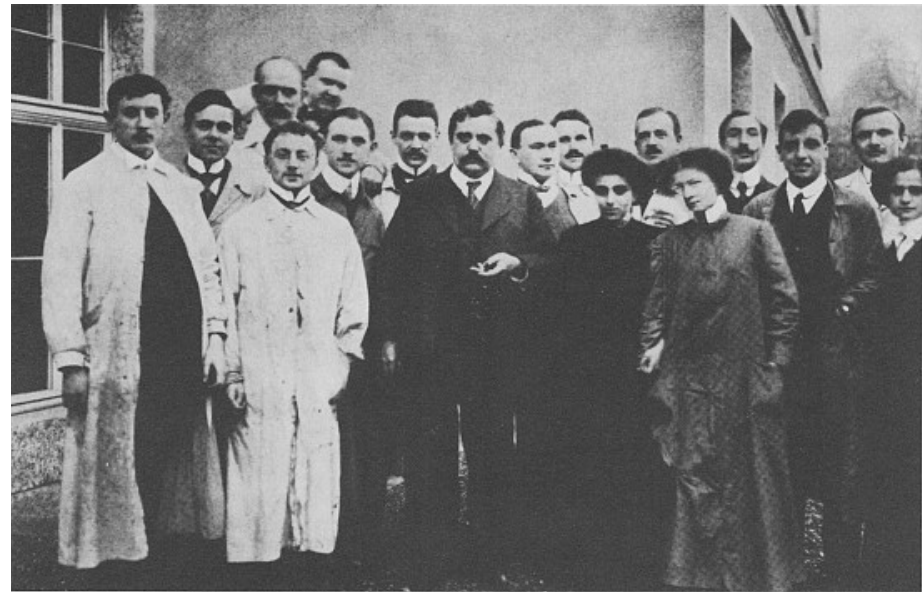

Fig. 10. Alfred Werner with doctoral students (from the left Paul Karrer, to the right of Werner, Hedwig Kuh, Sophie Matissen, far right, Chana Weizmann, sister of the first President of the State of Israel)

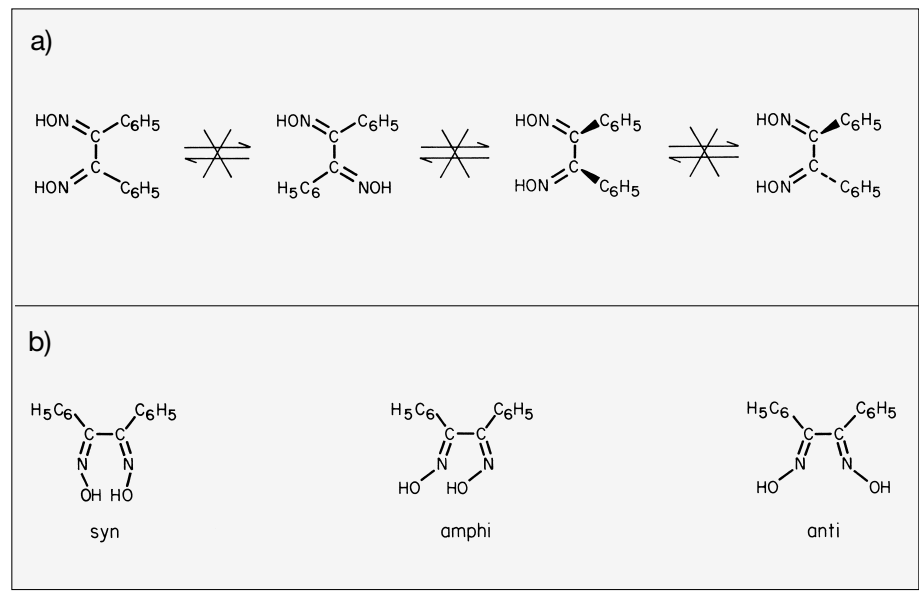

Scheme 4. a) Four benzil dioxime isomers according to the theory of V. Meyer and K. Auwers (1888); b) The three isomers according to the theory of A. Werner and A. Hantzsch (1890) 


\section{The Periodic System}

Werner was the first to recognise that the periods in the periodic table could have different lengths: after two short periods with eight elements each he placed two periods each with 18 elements. These conclusions were confirmed brilliantly and unexpectedly ten years later by the new atom model from Rutherford-Bohr and the Pauli Principle. Further predications that Werner made about the existence of new elements have however turned out to be incorrect.

\section{The Coordination Theory}

Werner is known principally as the author of the coordination theory and the related valence theory. At the beginning there was a break with tradition and a new concept for the structure of metal-ammine complexes. It was extended later by experiments that confirmed the theory and held Werner's attention for the rest of his life. It was here that he showed himself to be a tenacious and single-minded scientist, an industrious and systematic collector so that at the end a new scientific field of incredible order and systematic had been created.

If we compare the generally accepted formulism of metalammines at the time from S. M. Jörgensen with that of Werner, the break with the unitarian valence scheme going back to Kekülé becomes obvious (Scheme 5).

The use of a 'trivalent cobalt atom' and a 'pentavalent nitrogen atom' and the not unreasonable assumption that only the halo- gen atom attached to the nitrogen can be easily exchanged helped the formulism to be accepted. From his experience in organic chemistry Werner must have been troubled by the formulism of a chain of 'pentavalent nitrogen atoms' (hydrazine was first prepared in 1899 by Curtius; triazine, his $\mathrm{NH}_{2}$ homologue, has never been isolated). Werner never worked in this field himself. But apparently he knew the relevant literature down to the last detail and included the known examples of isomerism into his reasoning. The possible arrangements of the six ligands around a central atom shown in Scheme 6 allow in the case of $\left[\mathrm{MeB}_{2} \mathrm{~A}_{4}\right]$ three isomers for $\mathbf{8}$ and $\mathbf{9}$ but only two for 10. The (sparse) experimental evidence had never produced more than two isomers for $\left[\mathrm{MeA}_{2} \mathrm{~B}_{4}\right]$. Since only one isomer was known for $\left[\mathrm{MeAB}_{5}\right]$, a symmetrical arrangement must be present ( 8 or 9 or 10).

The elegant formalisms of Werner ${ }^{[5]}$ were vehemently rejected by Jörgensen, the recognised expert of the time. As a consequence Werner was forced to synthesise time and time again examples of suitable complexes to prove his theory.

A series of complexes with complex charges ranging from $3^{+}, 2^{+}, 1^{+}, 0,1^{-}$, $2^{-}, 3^{-}$, synthesised with Arturo Miolati attracted much attention. The complexes were prepared by stepwise replacement of neutral ligands with charged ligands and the charge was determined by conductivity measurements. Jörgensen countered with new formulations. He also rejected the interpretation of the cis/trans isomerization in planar quadratic $\mathrm{Pt}(\mathrm{II})$ complexes (11 and 12, Scheme 7) in 1896. The cis/ trans violeo salts $\mathbf{1 3}$ and $\mathbf{1 4}$ that were so important for Werner's theory, were not synthesized until 1907. Finally Jörgensen accepted the octahedral structure. The highpoint was achieved by Werner in 1911 when his American PhD student Victor L. King succeeded in separating the enantiomers of $\left[\mathrm{CoClNH}_{3}\left(\mathrm{NH}_{2} \mathrm{CH}_{2} \mathrm{CH}_{2} \mathrm{NH}_{2}\right)_{2}\right]^{2+} .2 \mathrm{X}^{-}$ predicted by his theory with the help of diastereomeric bromocamphersulfonates (enantiomers of $\mathbf{1 5}$ and 16) (Scheme 8).

The resolution was easily performed and the facile racemisation initially feared by Werner did not occur. ${ }^{[56]}$ The result stunned the world of chemistry and beyond and made Werner world-famous. This reaction may seem extreme from our point of view today since the resolution in principle only proved the octahedral arrangement of ligands around a $\mathrm{Co}(\mathrm{II})$ atom. But the reaction to this result revealed much more than was obvious at first sight. Many chemists still clung to the semi-mystical belief that 'optical activity' could only be associated with 'life' and 'asymmetric carbon' although optically active quartz and other minerals had been known for a long time. Werner dismissed any final doubts when he succeeded in 1914 in resolving the tetranuclear cobalt complex 17 (Scheme 9) into its enantiomers.

The number of complexes of $\mathrm{Co}, \mathrm{Cr}, \mathrm{Fe}$, $\mathrm{Rh}$ and Ir that Werner and his coworkers

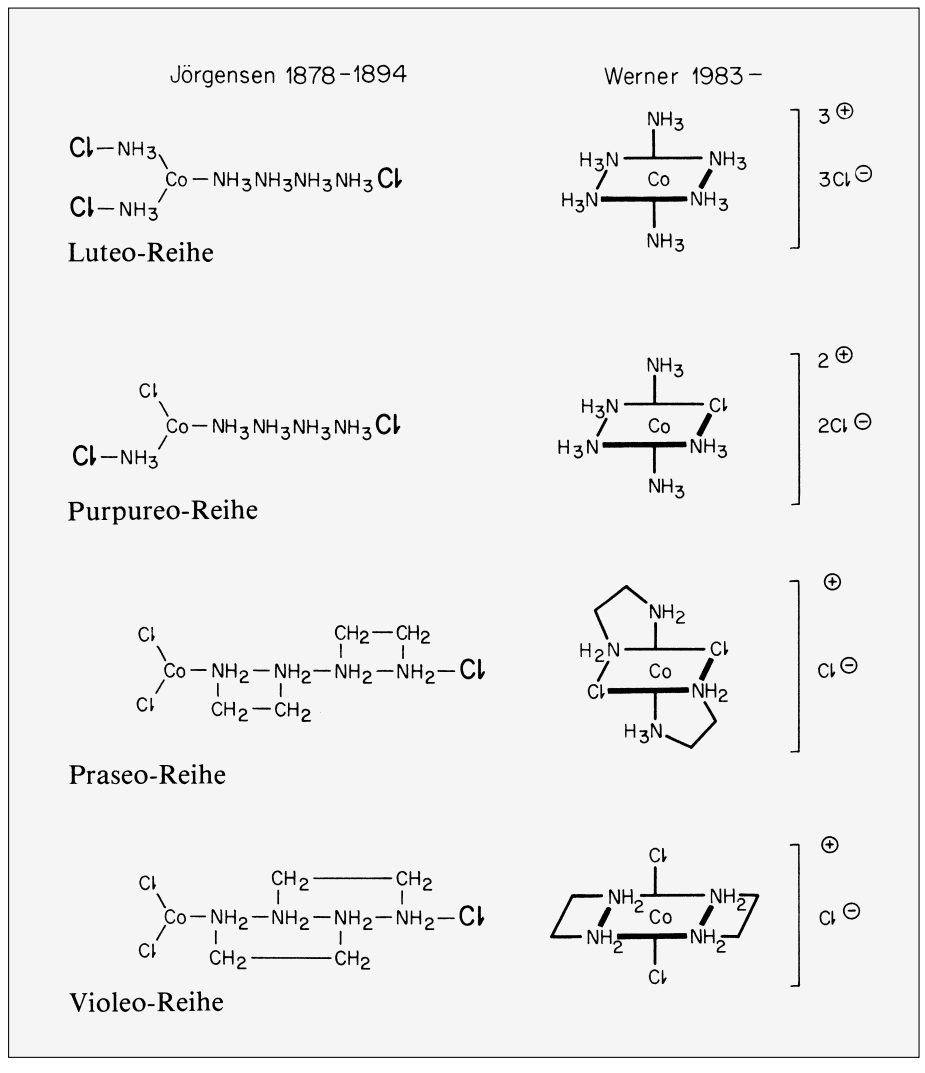

Scheme 5. Formulation of metal ammine complexes

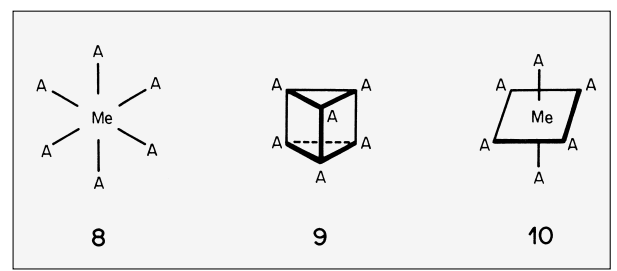

Scheme 6. Planar, prismatic and octahedral formulation of type $\mathrm{MeA}_{6}$

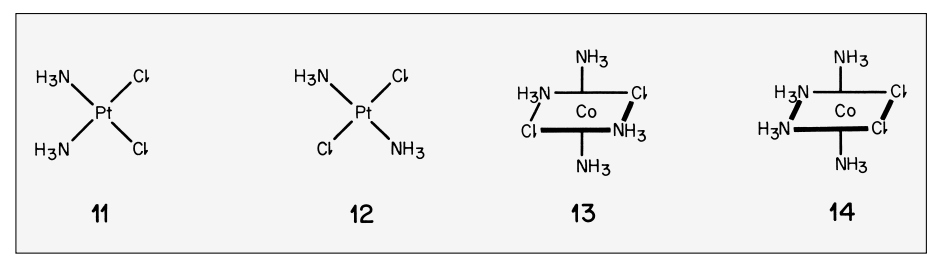

Scheme 7. Planar Pt(II) complexes, cis/trans Co(III) complexes

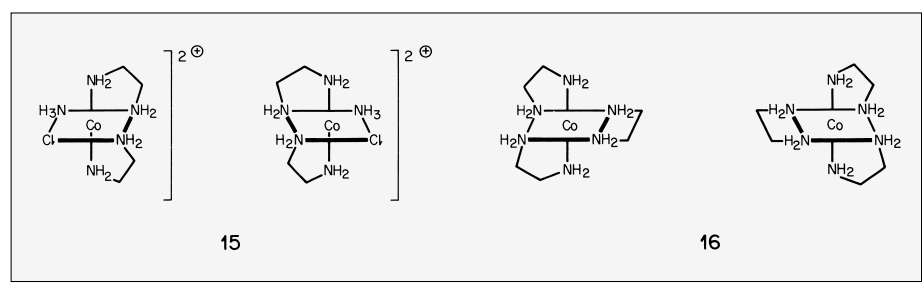

Scheme 8. Enantiomeric cobalt complexes 


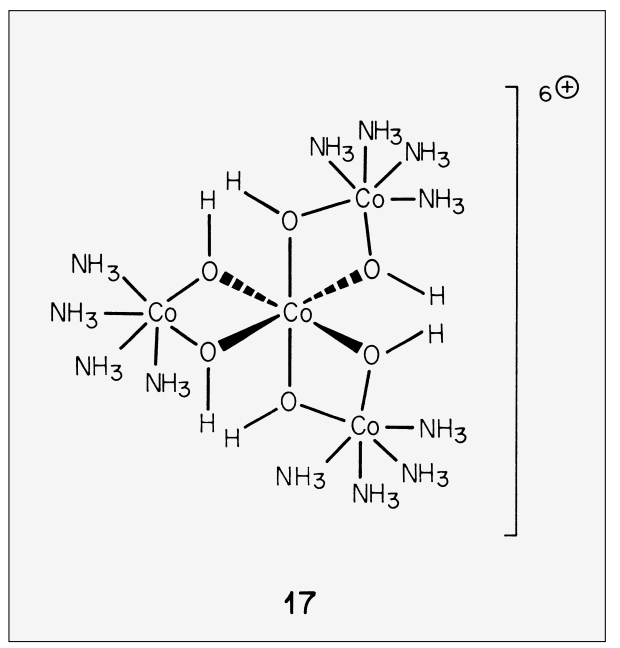

Scheme 9. The optically active carbon-free cobalt complex

succeeded in resolving into their enantiomers is very large. 'Rotate and resolve' were common terms in the institute. ${ }^{[57]}$

When the first X-ray structure analyses were published in 1914 by Bragg and Bragg, P. Pfeiffer and P. Niggli recognised immediately that the crystal structures corresponded perfectly with Werner's coordination theory. Further developments, with the exception of a passing mention of the modern textile dyes with chelated $\mathrm{Cr}$ (III) and $\mathrm{Co}$ (III) central atoms and the anti-cancer platinum complexes, will not be discussed here. Werner's concepts have become part of everyday chemical knowledge to such an extent that some modern textbooks in General Chemistry no longer even mention his name.

\section{The Great Honours}

On 11th December, 1913 Alfred Werner was awarded the Nobel Prize for Chemistry as the 14th chemist and the first Swiss. Werner's Nobel lecture can be read in ref. [58]. In Zurich he was honoured by the authorities, colleagues and especially the students with an enthusiasm that demonstrated in a wonderful manner the pride in Werner and effusive belief in science that that generation had. The Swiss Chemical Society held a symposium in the name of its most prominent member on 2nd May, 1914 in Neuchatel, the Werner medal was created and the Werner Prize for young scientists. The long list of honours that Werner received during his lifetime is presented in ref. [29]. Werner's 100th birthday on 3rd September, 1966 was marked in Zurich by the Swiss Chemical Society with a symposium and another from 5th-9th September in St. Moritz.

Werner was also commemorated in 1966 by the American Chemical Society. ${ }^{[51]}$ The interesting and informative biography by G. B. Kauffmann ${ }^{[29]}$ was also published on Werner's 100th birthday.

\section{The Tragic End}

Werner was ill long before it became obvious to others. He suffered from strong headaches lasting days. Excessive workload, cigarettes, alcohol abuse and demands from all sides destroyed even his strong constitution. From 1915 onwards his physical decay was obvious even to outsiders. ${ }^{[59]}$ Towards the end of the summer semester 1915 , Werner asked for his first leave of absence from the authorities. In the winter semester 1915/16 his lectures had to be held at times by Prof. Pfeiffer (who replaced him entirely in summer semester 1916); and in the following semester by his assistant Agthe. In February 1917 Werner took another leave of absence; in summer semester 1917 he was also unable to lecture. Abeljanz took over the temporary directorship of Department A. In the winter semester 1917/18 Werner tried to hold his lectures again and to run his department. It was to be his last return. His memory had become erratic, he often forgot the names of his doctoral students and although he prepared his lectures sentence by sentence with the help of his assistant, they were often barely comprehensible. ${ }^{[60]}$ In the summer semester 1918 some of the Werner's students sent a petition to the Erziehungsrat asking for the 'untenable situation' to be resolved.[61] Werner was sent on leave again. For winter semester 1918/19 the newly elected associate professor Paul Karrer took on the lecture courses and the directorship. With a letter to the Erziehungsdirektion from 6th May, 1919, Frau Prof. E. Werner requested that her husband be released from his position. Werner's resignation became official on 15th October, 1919. He died in the Burghölzli clinic on 15th November 1919.

Dissertations on Werner's projects continued to appear until 1922 (the last was in 1929). They were supervised by younger colleagues. It is probable that many results from the final years were never published, particularly those with spectroscopic and chiroptic measurements.

When one considers that the publications of Werner do not contain a single patent, and that his research did not make any claim to practical application, one could ask why so many talented students came to work with him in his early years. They would not learn any novel laboratory techniques that would be of direct use in their later careers apart from exact observation and careful analysis. I tend today to assume that Werner's attraction stemmed from the fact that everyone close to him understood that this scientist was devoted to pure research and that he gave all his strength for a comprehensive and significant idea.

\section{Paul Pfeiffer and other Lecturers at the Institute of Chemistry}

A large group of lecturers soon began to gather around Werner. They extended and supplemented the range of lecture courses on offer, for example:[62] Roland Scholl* (summer semester 1893-winter semester 1895/96) later in Karlsruhe, Graz and Dresden; August Bischler (winter semester 1893/94-summer semester 1899), whose name is known in the literature through his isoquinoline synthesis; Franz Feist* (summer semester 1984-winter semester 1900/01), later went to Kiel, he was responsible for the well-known rearrangement of a pyrone to so-called 'Feist acid'; Karl Kippenberger* (winter semester 1895/96), later in Jena, Cairo, Königsberg, Bonn; Walter Dilthey* (winter semester 1904/05-winter semester 1907/8), later in Cairo, Erlangen, Bonn, he was a well-known dye chemist and the teacher of Robert Wiziger, Adolf Grün (winter semester 1907/08-summer semester 1912), a lipid chemist who was the first to synthesise a cephalin and a lecithin; Gustav Jantsch (summer semester 1911-winter semester 1919/20) later in Karlsruhe, Bonn, Graz; Israel Lifschitz (winter semester 1914/15-summer semester 1921) a physical chemist and spectroscopist; Jan Vaclav Dubsky (winter semester 1914/15-winter semester 1919/20) later went to Groningen, Brno; David Reichinstein (winter semester 1911/12-summer semester 1916); Oskar Baudisch (summer semester 1912-summer semester 1916), discoverer of copperon.

The only lecturer that will be discussed at length here is Paul Pfeiffer (21.4.1875 Elberfeld - 4.3.1951 Bonn) (Fig. 11). He completed his dissertation under the supervision of Werner in 1898 on 'Molecular Compounds of the Halogenides with Tetravalent Tin and Tin alkyls', worked as a post-doc with Ostwald in Leipzig in 1899 and with Hantzsch in Würzburg in 1900. In the winter semester 1901/02 he completed his habilitation at the University of Zurich. Werner valued him as an assistant and later as a colleague. The pair, deep in discussion as they walked through the corridors, became a familiar sight:

"Es geht der Alte durch's Labor gefolgt von Doktor Pfeiffer

Es schweigen alle Gesänge bald,

Es regt sich ries'ger Eifer"

(from the Bierzeitung[29]).

(The Boss walks through the lab Followed by Doctor Pfeiffer All songs quickly fade away To be replaced by great fervour) 


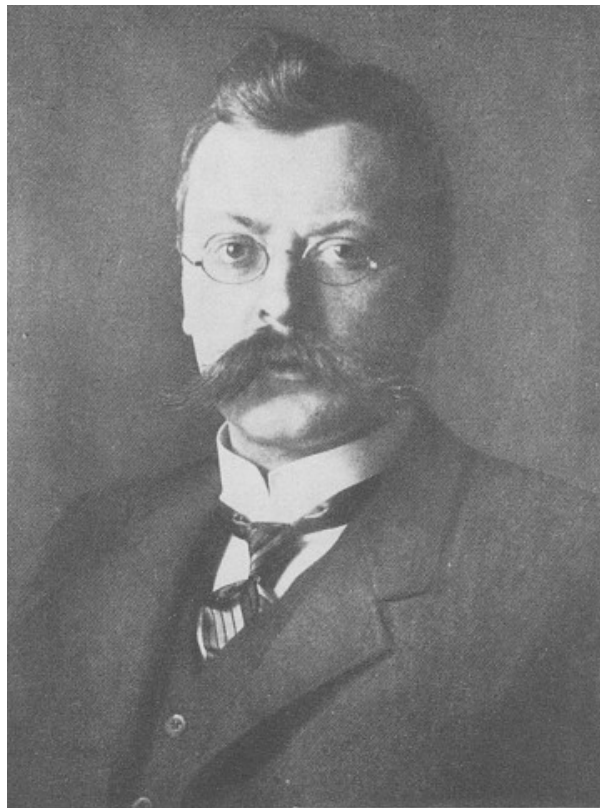

Fig. 11. Paul Pfeiffer

Pfeiffer's research concentrated initially on complex chemistry involving tin compounds. Handling alkyl-tin compounds led to poisoning which nearly cost him his sight.

Somewhat later Pfeiffer took up new topics, e.g. the determination of cis/trans isomerisation in stilbenes and cinnamic acids, halochromism, light reactions of $o$ nitrostilbenes, complexes of nitroaromatics and alkenes (now known as chargetransfer complexes). He strove to become independent and to gradually move away from the overwhelming influence of Werner. There do not seem to have been disagreements, however, since Pfeiffer's respect for his former teacher was too great. A serious estrangement occurred at the outbreak of the First World War however: Werner was inclined towards France whereas Pfeiffer remained loyal to the German Empire. At a time when Werner was already ill, Pfeiffer left the Institute of Chemistry in the winter semester 1916/17 and took up a professorship at the University of Rostock. ${ }^{[63]}$ After the end of the war he moved to the Technical University Karlsruhe (1919) and subsequently as the successor to R. Anschütz at the University of Bonn in 1922, where he became Rector in $1931 / 32$. He retired in 1947 . It is not possible to discuss here the many publications that originated from his time in Germany. ${ }^{[64]}$ Looking through his book on molecular compounds, ${ }^{[65]}$ which was very popular at the time, one is amazed how strong Werner's influence was in inspiring him to attempt to bring a similar order to the field of 'molecular compounds'. Ultimately Pfeiffer failed in his attempt because he tried to unite too many unconnected aspects.

\section{Female Students of Chemistry}

The University of Zurich had allowed individual women to study from 1840; see refs $[3,35]$. A fundamental decision was not made until Nadeshda Suslowa from Petersburg applied for admission to the Medical School. The liberal ruling caused a great amount of attention and her dissertation in 1867 must be regarded as a pioneering act by the University. The first woman to study chemistry at the University and to be awarded her Dr. phil. was Lydia Sesemann from Wiborg, Finland. Her dissertation, made under the supervision of Merz and Weith, was entitled 'Dibenzylacetic Acid and New Syntheses of Homotoluic Acid'. Geuther had discovered acetoacetic ester in 1865 and later its use in synthesis by metallation and reaction with alkylhalides became well known. Lydia Sesemann successfully transferred this technique to ethyl acetate.

In 1887 Rachel Lloyd from Philadelphia completed her dissertation in English (!) on the synthesis of ring-substituted anilines from homologous phenols, supervised by Merz. Whether Ira Moore (1890) is a man or woman cannot be ascertained from the dissertation.

From 1900 many women completed their doctorates in Werner's group. For example Edith Humphrey from London (1901); Anna Dorn from Naundorf near Dresden who studied the conductivity of many carboxylic acids (1905); Dora Stern from Göttingen who worked on nitrophenanthrenquinones; Cornelia Geissler from Neumarkt, Galicia (1907); Chana Weizmann from Pinsk Russia, the sister of the first President of Israel (1912) (Fig. 10). The first Swiss woman was Jeanne Schwyzer, born in 1891 in New York (Fig. 12). She studied at the Bryn Mawr College and then moved to Switzerland with her parents in 1911, where she took the Eidgenössische Maturität and started to study medicine. Then apparently impressed by the lectures of Werner, she transferred to the Philosophical Faculty II and began her studies in chemistry. Her dissertation (1919) was on optically active chelate complexes of cobalt In 1920 Jeanne Schwyzer married the wellknown Professor of Pharmacy at the ETH, Robert Eder.

Many women have undertaken research in chemistry at the University since then, but they were always in the minority compared to their male colleagues and therefore unsurprisingly often at the centre of attention in the laboratory.

\section{The Zurich Chemical Society}

The 'Chemische Harmonika', the predecessor to the Zurich Chemical Society, has already been mentioned in the Section

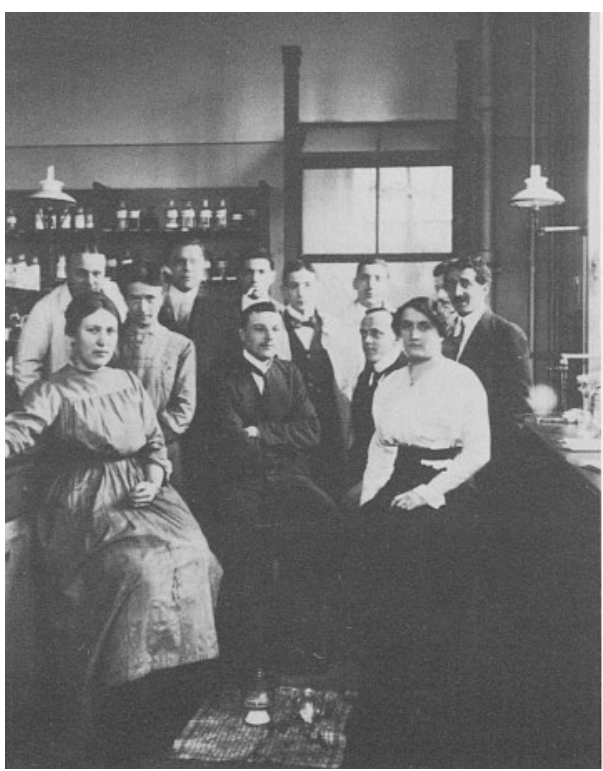

Fig. 12. Doctoral students (ca. 1916): left Jeanne Schwyzer, Lina Lang, Fritz Fröhlich (seated in the middle), Natalie Zaremba (?)

on Wislicenus. The founding members included Bolley and Kenngott (Polytechnic), Merz, Weith and Wislicenus (University). Fifty-seven members were registered for the opening meeting on 4th July 1870 . For many years, eight to twelve meetings were held per year in various restaurants in the town. Topics of discussion were always current research. The desire to report appeared to be so great that it became necessary to introduce a rule that no new lecture should be started after 10 o'clock in the evening.

Transcripts were written for almost every meeting, up to 1948 . From then on they have either been lost or were no longer recorded. Well-known names such as $\mathrm{R}$. Gnehm, W. D. Treadwell, E. Berl, W. Kuhn, F. Ebel, T. Reichstein, M. Furter, K. Bernhard, O. Gübeli, H. Schmid can be found under the transcript writers.

In 1920 the committee decided to invite external speakers. On 11th May 1923 for example, Heinrich Wieland spoke on 'The Chemistry of Bile Acids', on 1st May 1925, Robert Emmanuel Schmidt reported on 'The Field of Anthraquinone Dyes' and on 28th May 1925 Hans Fischer on 'Blood Pigments and Porphyrines'.

From 1920, in addition to the Guild houses 'Zur Zimmerleuten', 'Zur Waag', etc. the lecture theatres of the ETH and University were used for meetings. For many years lecture theatres at the University and ETH have been used alternately.

The Zurich Chemical Society was vital as a meeting point between the colleagues of the ETH and the University and as a symbol of the scientific activities undertaken in Zurich. However its significance has been gradually eroded by the many activities of the individual institutes holding their own colloquia and invited lectures. 


\section{The Karrer Era Election and New Orientation}

In his recollections of Prof. Werner, Karrer wrote:[28] "It was the time of the First World War. This had far-reaching consequences also for the Institute of Chemistry. The many foreign students, particularly the Russians and Poles, departed like a swarm of bees and attempted to reach their homelands. Most of few Swiss chemistry students had to report for duty at their military units. The lecture theatres and the laboratories emptied; there was a feeling of depression throughout the building. This increased when Prof. Pfeiffer was appointed to the Chair in Chemistry at the University of Rostock and announced that he intended to take it up. When the writer (Paul Karrer) entered the Institute as associate professor in spring 1918, there were only five doctorate students left."

Paul Karrer was appointed as associate professor and successor to Pfeiffer on 15th April 1918, with the obligation to lecture for 6-8 hours a week and a basic salary of $5,000 \mathrm{sFr} .{ }^{[66]}$ At the same time his former 'Lehrauftrag', which was entitled 'Physical and Theoretical Chemistry', was altered to 'Aromatic and Special Fields of Organic Chemistry'. Specifically mentioned were: dyes, alkaloids and heterocycles, terpenes and camphor, proteins, glucosides and sugar, stereochemistry. It is astonishing and unexplained why three semesters after Pfeiffer's departure passed before a successor was named. Particularly because the decision to appoint Karrer was unanimous in both the Faculty and the University Commission.

The request to appoint Karrer was based literally in part on the extensive recommendation from Werner dated 28th January $1918,{ }^{[60]}$ in which he analysed the situation with clarity and vision and in which he assessed the possible candidates Adolf Grün, Ernst Berl, Paul Karrer, Adolf Kaufmann and Julius Schmidlin. Werner wrote about Karrer, whom he had unhesitatingly placed at the top of the list of candidates: “... his research demonstrates a versatility that indicates a fundamental treatment of the problems......and shows that Dr. Karrer works with a clear vision and particularly with excellent technical skills in the diverse areas of physiological and therapeutically significant chemical compounds....I am convinced that these qualities ensure that Dr. Karrer will become a very successful scientist...."

Paul Karrer ${ }^{[67]}$ was born as a citizen of Teufenthal AG on 21st April 1889 in Moscow to Dr. Paul Karrer, a dentist, and his wife Julie (nee Lerch). In 1892 the family returned to Switzerland and lived for three years in Erlenbach on the lake of Zurich before settling in Wildegg. He went to pri- mary school in Möriken, secondary school in Lenzburg and then grammar school in Aarau. In 1908 he began his studies in chemistry at the University of Zurich, which he had already completed by 1911 with a dissertation entitled 'The Valence Isomerisation of Cobalt' ${ }^{[71]}$ After three semesters as a teaching assistant to Werner, he transferred to Dr. Paul Ehrlich at the Georg-Speyer Haus in Frankfurt a.M. He was promoted to head of the chemical department already by 1915. Prof. M. Freund, Director of the Chemistry Laboratory of the University of Frankfurt, was so impressed by Karrer that he invited him to submit his habilitation to the Science Faculty. It is not known why Karrer did not take up this offer.

When Werner retired in 1919, finding a successor for the most important Chair of the Faculty posed a big problem. Karrer was put forward as a candidate but the proposal only received eight votes, whilst Pfeiffer and Karrer as a team received four votes with Pfeiffer as the direct successor to Werner. ${ }^{[72]}$ In an almost unbelievable manner the minority on the Faculty sought further recommendations ${ }^{[73]}$ and in doing so directly confronted the Erziehungsdirektion and the majority of the Faculty who were of the opinion that Karrer was more versatile and more scientifically capable than Pfeiffer. The Hochschulkommission then stated in a careful comparison of the two candidates and with remarkable clarity that if Pfeiffer had not left Zurich three years earlier he would undoubtedly have been appointed Werner's successor. The possibility of three chemistry professorships was also considered (i.e. including Abeljanz, who would not retire until 15.4.1921). However there were strong reservations due to the close similarity in the research fields of Karrer and Pfeiffer and because such a decision would delay the introduction of new and important areas such as physical chemistry for many years. Finally the Hochschulkommission found out from Pfeiffer that he was willing to return to Zurich but only under the condition that he would take over the directorship of the institute with no restrictions whatsoever. This and the recognition that Karrer's clear tendency towards a physiological basis in organic chemistry "which for a teacher with many medical students" give him a clear advantage in this respect, led to a decision: the Hochschulkommission voted Karrer unanimously as "Head of the Chemical Institute"; the Cantonal Government confirmed the appointment on 16th October 1919.

From that moment Karrer (Fig. 13) executed with care and utmost sensitivity the decisive reorientation of the Institute:[74] The Department of Physical Chemistry was created on 15th October 1920 and Victor Henri was appointed as professor (see Section 10). Prof. W. D. Treadwell from the ETH (where he had lectured for seven semesters) took over responsibility for modern qualitative analysis, food science went to Dr. Baragiola, Cantonal Chemist, who lectured in the subject for six semesters, and for synthetic organic chemistry and terpene chemistry Karrer was able to persuade Dr. Leopold Ruzicka to leave the ETH. Ruzicka completed his habilitation in winter semester 1920/21 and lectured for nine semesters at the University. The great respect that Karrer had for Ruzicka and the friendly relationship that they shared in the early years is reflected in the recommendation that Karrer wrote for Ruzicka for the Faculty in July 1920.

In addition to the above-mentioned lecturers, Jantsch, Lifschitz (lectured on physical chemistry I and II, electrochemistry, photochemistry), Dubsky and Agthe were members of the teaching staff. Several of these however were frequently on leave and soon left the Institute permanently. After a short time Karrer appointed more staff, who will be described below.

A microanalytical laboratory for the institute was installed very quickly, since Karrer was well aware of the time delay and fluctuating reliability when the compounds were analysed by the person who had synthesised them. Many of the chemists from that time will remember Dr. Gertrud Bussmann who ran the microlab for many years.

It is clear that the reorientation of the research and the systematic improvement of the Institute infrastructure were some of the most important decisions that Karrer made at this early stage. They formed the basis upon which the Institute prospered. In fact at the time no-one had been able to break free of Werner's areas of expertise. This only

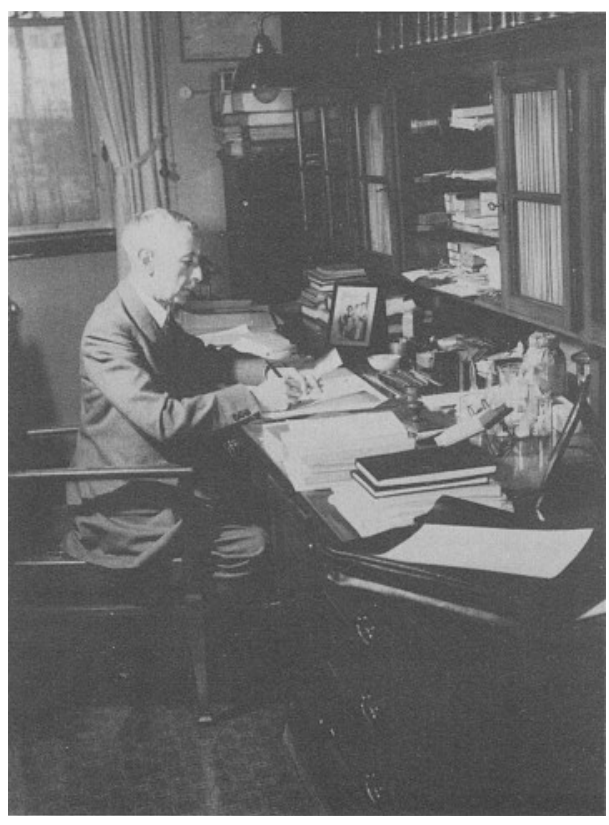

Fig. 13. Paul Karrer 
became possible later once the theoretical foundation of atomic structure was created. From today's point of view it can be considered good fortune that Pfeiffer, the 'natural' successor to Werner was not appointed.

\section{Karrer's Scientific Achievements}

During the extraordinarily long time span of 47-years academic research as a Professor and Director, in addition to six productive years as an assistant and almost ten years as an active emeritus Professor, Karrer produced a truly impressive body of work, which due to its range and variation through many very different fields can only be described here fleetingly. Karrer's biography contains 1042 original publications in scientific journals, including review articles and conference reports. In addition he authored 78 patents. The 'Textbook of Organic Chemistry' that was published in 14 editions between 1927 and 1963 and translated into seven languages should not be forgotten as well as the monograph 'The Carotenoids' which he cowrote with E. Jucker. Karrer revised his textbook incessantly and - with respect to content - adapted it to reflect new results. It is internationally one of the most successful textbooks in chemistry ever.

The topics of the publications of Karrer and his group between 1912 and 1925 reflect the influence of P. Ehrlich's introduction of modern chemotherapy and the impressive work on natural products by the great Emil Fischer. Much later Karrer spoke to me of Fischer with great respect. Initially research on physiologically active arsenic and bismuth compounds dominated. This was directly connected to 'Salvarsan' (Ehrlich, 1910), the correct structure was however only determined many years later. At the same time Karrer worked on the structure elucidation of alkaloids (emetine and sanguinarin groups). Synthesis of arylketones, partially in connection with vermicidal filicic compounds followed. Synthesis of glycosides were extensively investigated in addition to more tentative examination of quinic acid, quercitol, glycyrrhetinic acid, tanning agents, amyloses, inuline, suberine (cork fat), and chitin. Despite some encouraging results (in addition to some wrong conclusions) these publications do not make a lasting impression on the reader, disregarding subsequent developments, since the work tended to be fragmentary and did not provide any new insights.

One of the first specialities was Karrer's publications on polysaccharides ( $\mathrm{ca} .50 \mathrm{ar}$ ticles between 1920 and 1930 on starch, cellulose, inuline, glycogen, lichenine, chitin, xylan). These articles brought him international recognition - but neither Karrer nor any other specialists in the field was able to find the key to the molecule structure of the polysaccharides. This was achieved by Hermann Staudinger (ETH), whose fundamental new concept of the covalent bonding of monomeric units to build a macromolecular chain ultimately triumphed over all other theories.

Karrer and his group made great progress in the new field of the configuration of proteinogenic amino acids: With early ORD comparisons he was able to derive the uniform configuration of the amino-substituted carbon atom and demonstrated the same configuration in alkaloids, e.g. in nicotine. The investigations into the synthesis of amino-alcohols by reduction of amino-carboxylic acids and their use in the production of local anaesthetics e.g. 'Panthesin' (patents 1920 and 1922) directly evolved from the above research.

The most comprehensive series of investigations with a common theme was the 'plant dyes'. This work began in 1927 and formally ended in 1935 with the 63rd publication. At the beginning were the investigations into anthocyanine, the red watersoluble dye contained in many flowers and fruits. Improved separation techniques and degradation methods enabled Karrer and his coworkers to determine the structures of many anthocyanines. Together with Richard Willstätter and Robert Robinson, Karrer was one of the recognised creators of classic anthocyanine research.

Polyene dyes of the terpene series were investigated at the same time. The first publication (1927) concerned the saffron dyes crocin and crocetin. From there Karrer progressed to become the internationally recognised master of natural product chemistry in only a few years:

\section{Correct symmetrical formula of crocetin}

1929 cis/trans-Isomers of bixines

1930 Structures of lycopene, $\beta$-carotene, luteine, zeaxanthine, squalene, chromatographic separations

1931 Isolation and structure determination of vitamin A (axerophthol)

1935 Synthesis of vitamin $B_{2}$ (riboflavine); carotenes in photosynthetic bacteria

1938 Synthesis of vitamin E (tocopherol)

1939 Isolation of vitamin $\mathrm{K}_{1}$ (phylloquinone)

1942 Structure of NAD ${ }^{+}$ ('codehydrogenase')

1945 Discovery of carotene epoxides; partial synthesis

1950 Synthesis of $\beta$-carotene

1955 Pterines from Drosophila

1958 Structure of toxiferine (curare alkaloid), synthesis of canthaxanthine
This overview can only show a few of the highlights of Karrer's research. They result from incredibly intensive research activities and active collaboration with talented doctoral students and assistants, demonstrated by the number of publications produced: 35 articles in 1934 followed by 39 the next year! Some of the results were obtained in competition with other research groups. The last extensive research topic, the investigation of curare alkaloids, began in 1945 and ultimately continued in close collaboration with $\mathrm{H}$. Schmid and a large number of assistants and reached a new highpoint in scientific knowledge and at the same time modernisation of laboratory techniques at the Institute. This field was continued far beyond Karrer's retirement and brought stimulating new ideas for the entire field of alkaloid chemistry. The same can be said for other areas of research that Karrer undertook or initiated. In 1932 George Wald, a postdoc, isolated vitamin A for the first time from the retina of oxen and thereby started the structural research into retinal pigments. When, in 1946 the first results into the composition of the mysterious glucoside aucubine (with H. Schmid) and verbenaline (with $\mathrm{H}$. Salomon) were published, none of the collaborators could have imagined that they had laid the foundations for a new chemistry of the group of iridoids.

Palustrine, the toxic alkaloid extracted from march horsetail, was the first spermidine alkaloid to be isolated in pure form in 1948. In 1951 fuerstion the first plant dye with a diterpene structure followed. To conclude the pteridines are mentioned, that were later further developed by the Viscontini group and were to become a significant group of therapeutic potential that even today has not been fully overviewed.

\section{Honours and Activities}

Karrer was honoured many times for his pioneering research. He was awarded the highest scientific prize in Switzerland, the Marcel Benoist Prize, in 1923, this was followed by the Cannizzaro Prize of the Italian Chemical Society in 1935 and, the high point, the Nobel Prize in 1937. In 1947 Karrer was elected as 'Foreign Member of the Royal Society' and in 1954 'Officier de la Legion d'Honneur'. No fewer than 15 Universities awarded him honorary doctorates and an even larger number of Academies and scientific societies made him an honorary member. Despite all these honours Karrer remained the same reserved and modest scientist, although he was happy to accept the honours awarded to him. Karrer was an active participant in many committees; president of the Swiss Chemical Society (1924-1926), the Zurich 
Society for Natural Sciences (1928-1930), the Stipendienfonds of the Swiss Chemical Industry (1944-1967), member of the editorial committee of Helvetica Chimica Acta (1924-1971), Dean of the Philosophical Faculty II (1928-1930), Rector of the University (1950-1952) and president and organiser of the International Union of Pure and Applied Science Congress which took place in 1955 in Zurich.

Since 1959 a foundation created by leading companies of the Swiss chemical industry has kept alive the memory of this great research scientist at the University with the 'Paul Karrer Lecture'. [75]

It is difficult, if not impossible, to compare Karrer's lifelong achievements with those of his teacher Werner. The differences in personal and scientific respects are too large. Despite that it is clear that Karrer took over much more from Werner than is generally supposed. However the difference lies in the fundamental nature of the topics that the two scientists chose to work on. Werner developed very early on a comprehensive concept for the structural understanding of a large but neglected field of chemistry and built upon this basis a lifelong with tenacity. It is difficult to imagine inorganic chemistry today without the influence of Werner's reasoning. Economic considerations were obviously not what drove Werner and he did not seek practical application of his work.

The so-called 'relevance' of Karrer's achievements is obvious; in his bigger and more sensational research it was always the proven or proposed biological activity of target compounds that inspired him to investigate. For this reason the influence of Karrer's research on the development of the chemical industry is evident.

Who could decide which fundamental quality for a university professor is the more significant or perhaps more far-reaching? Both Werner and Karrer, each in his own time, made his field flourish, both were acknowledged experts of their respective specialities and both offered research topics that held great attraction for young chemists.

\section{Professors at the Institute of Chemistry at the Time of Karrer}

After the departure of the last lecturers that had habilitated under Werner, and after the retirement of Abeljanz, the path was free for the creation of a Chair in the Department of Physical Chemistry (Henri's appointment had already been confirmed at an earlier date) and the Sections A and B were united under a single Institute Director. Two positions as departmental heads were created from the associate professorships for, the one hand, the practical teaching for medical students and this post was occupied by Charles Gränacher in 1924 and the other, for prospective school teachers, by Ernst B. H. Waser. Gränacher was a former student of Dubsky, who then worked as an assistant for Werner and Karrer and taught part-time at the secondary school in Rafz and at the Zurich grammar school. In winter semester 1920/21 he completed his habilitation in organic chemistry. Gränacher's scientific work was concerned with improvements in Pregl's microanalysis of halogen-, sulfur-, and nitro-containing compounds. His major area of research later was investigations into the oxidation of paraffins to fatty acids and the reaction of rhodanin with a range of electrophiles to form dyes. When the Erziehungsdirektion turned down the proposal of the Faculty to elect him associate professor in 1928, he transferred to Ciba where he soon made an impressive career.

Ernst Waser completed his doctorate with Willstätter at the ETH on the synthesis of cyclooctene derivatives from pseudopelletierine and after working as an assistant to H. Wieland (Munich) and Cloetta (pharmacology, University of Zurich) took a position as chemist at the 'Allgemeine Maggi-Gesellschaft' in Kempthal. He completed his habilitation in winter semester $1921 / 22$ in organic chemistry and was then appointed as part-time lecturer for the practical course for teacher training candidates, before being promoted to department head. Waser also lectured on food chemistry at the ETH. The appointment as Cantonal Chemist (1928) and the part-time professorship for food chemistry (1930) enabled him to satisfy his desire for a responsible position in public office and his preference towards university teaching simultaneously.

Waser lectured at the University on a wide range of subjects (technology, dyes and pigments, alkaloids, food chemistry, protein chemistry, synthesis of pharmaceuticals, heterocycles, water- and wastewater purification, and a course on dyeing techniques). His research concerned principally hydrogenation, decarboxylation and synthesis of aromatic amino carboxylic acids. His premature death in 1941 left behind a great void. ${ }^{[76]}$

The successor to Waser for the position of section head was Karl Wilhelm Nägeli. He began his dissertation in Werner's group and completed it with Karrer in 1921. After a position as Ramsay-Memorial Fellow at the University of Oxford and research on physical chemistry topics under the supervision of Prof. Lambert he returned to the University of Zurich and made his habilitation in chemistry in winter semester of 1925/26. Nägeli wrote a short textbook of chemistry for medical students in which he attempted to introduce modern electron theory of the English School (R. Robinson, Lapworth etc.) into the German language. His scientific interests were aimed at the Curtius degradation and its application to structural problems (perhydronorbixin, chaulmoogric acid) and the synthesis of sulfonamides with pyridine substituents. ${ }^{\text {[77] }}$

Gerold Schwarzenbach followed Gränacher as section head (winter semester 1930/31). His research interests are described in Section 12.

Robert Wizinger was appointed in summer semester 1938 as senior lecturer and titular professor. He was awarded his doctorate at the University of Bonn in 1924 under the supervision of Prof. Pfeiffer and completed his habilitation in 1934. Shortly after being promoted to associate professor in Bonn he was dismissed for political reasons and arrived as a penniless refugee with his family in Switzerland. The appointment as section head and a new habilitation for the field of 'organic chemistry and organic technology' enabled him to continue with his academic career. In summer semester 1943 he was elected associate professor. Wizinger hesitated for a long time whether he should take up the offer of the Chair in the newly created Institute for Dye Chemistry at the University of Basel, particularly because Karrer and the Faculty were attempting to improve his research facilities. In 1947 Wizinger accepted the position in Basel and left Zurich.

Wizinger brought a new style of working to Zurich, which differed greatly in its casual manner to the strictly organised Karrer. However many $\mathrm{PhD}$ projects under his supervision dragged out so much that it became difficult for some to bear. Wizinger also had a tendency to publish the results of his students very late or sometimes not at all. As a lecturer he filled us with enthusiasm with his lectures on aromatic chemistry that were peppered with humorous historical reminiscences. The Monday evening tutorials on synthetic chemistry were also very popular. These were continued, in a different format, by $\mathrm{H}$. Schmid and are today part of the advanced chemistry programme.

Wizinger's scientific interests were mainly focussed on dyes: mechanism of azo-coupling, synthesis of formazans, triarylmethanes, flavylium salts, cyanine and hemicyanine dyes. He was the first to describe correctly the ionic mechanism of bromo addition to olefins.

Robert Schwyzer obtained his doctorate with Karrer in 1948 and his habilitation in summer semester 1951 for special fields of organic chemistry. His successful teaching and research activities were not interrupted by his move to Ciba in March 1952. Schwyzer introduced the new and pioneering field of peptide synthesis to the research spectrum of the Organic Chemistry Institute. When he was elected Professor for Molecular Biology at the ETH in winter semester 1963/64 he discontinued his lectures at the University.

The research of Prof. Hans Eduard Schmid is described in Section 13. 


\section{Physical Chemistry from Victor Henri onwards}

\section{Background}

When Pfeiffer was appointed as associate professor at the beginning of the summer semester 1908, his contract specified teaching 'physical and theoretical chemistry'. After his departure this area was initially left vacant. From winter semester 1914/15 Dr. Israel Lifschitz began to lecture on topics of physical chemistry principally in courses that Karrer had newly defined.

On 5th January 1920, the Erziehungsdirektor Mousson asked the Philosophical Faculty II to make proposals for the successor to Abeljanz (see [74]). The Faculty tried initially, without success, to attract Dr. Arthur Stoll, head of the pharmaceutical department of Sandoz in Basel[78] (organic chemistry!) and then applied to not appoint anyone for the time being and to amalgamate Sections A and B to a single one under Karrer. At the same time an extensive reorientation of the teaching of physical chemistry at other Swiss universities was being undertaken.[79] Karrer emphasised in an expert opinion the necessity of creating a Chair in Physical Chemistry. The following candidates were considered: J. E. C. Timmermans, Brussels; E. Briner, Geneva; A. L. Bernoulli, Basel; and E. H. Büchner, Amsterdam. Büchner was put forward by the Faculty for the Chair but was turned down by Mousson after a personal interview. On 28th May, Mousson put forward the name of Victor Henri and requested the Faculty to discuss his suggestion. Henri had been proposed to him by the Coroner, Prof. Zangger. Recommendations for Henri were written by Pierre Weiss (Strasburg), Jean Perrin (Sorbonne) and Pierre Langevin (Collège de France). ${ }^{[80]}$ On 30th July 1920 , the Faculty put forward a proposal for primo loco Dr. W. Treadwell, Professor at the ETH, and secundo loco Dr. Victor Henri, Paris. Since Treadwell declined the Chair, Henri was appointed associate professor for physical chemistry on 15th October 1920 and at the same time given two assistant positions and a respectable budget for equipment. ${ }^{[81]}$

\section{Victor Henri[82]}

With this bold appointment, the University gained an open-minded and versatile scientist who founded a school of spectroscopy in Zurich that can be considered amongst the best in the world (Fig. 14). The son of a French man and a Russian woman, he spoke both languages fluently. He grew up in Marseille, Sebastopol, Riga and Petersburg. With 15 he moved to Paris. He studied physiology under Binet at the Sorbonne, was awarded his doctorate with a dissertation on physiology in Göttingen in 1897. Whilst working as an assistant at the Sorbonne with the physiologist Dastre he began to turn increasingly to aspects of physical chemistry. After the outbreak of war he was sent to Russia in 1915 on an official mission to help rebuild the chemical industry. The Russian revolution caused him to abandon this mission and he returned to France. From then on he concentrated on photochemistry and quickly gained international recognition for his research.

In Zurich Henri began by lecturing on 'General Physical Chemistry' and 'Applications of Physical Chemistry in Biology, Catalysis and Fermentation Reactions'. He also organised practical courses in physical chemistry for chemists and biologists. Under his supervision around 20 dissertations were completed that were almost all concerned with his photochemical research. Henri extended the quantitative methods for molecular spectroscopy. Many absorption spectra in the liquid and gas phases were measured. With time proven concepts on the correlation between structure and electronic spectra were developed, known today as chromophores. This research was greatly significant for the organic chemists who had started in the middle of the 1920s to tackle the structure of polyenes (P. Karrer, R. Kuhn). Henri discovered independently from Bodenstein that there were photochemical reactions in which a large number of molecules reacted per quantum of absorbed light. Today these are classified as chain reactions. Henri also discovered the phenomenon of 'predissociation' in molecular spectra, which showed a continuous transition from line to band spectra.

At the beginning of 1927, Henri was a guest lecturer at MIT, Cambridge, USA. In 1930 he resigned his professorship and became the director of an industrial research institute in Berre (South of France). After a short time he moved to a professorship at the University of Lüttich. In 1939 he was called

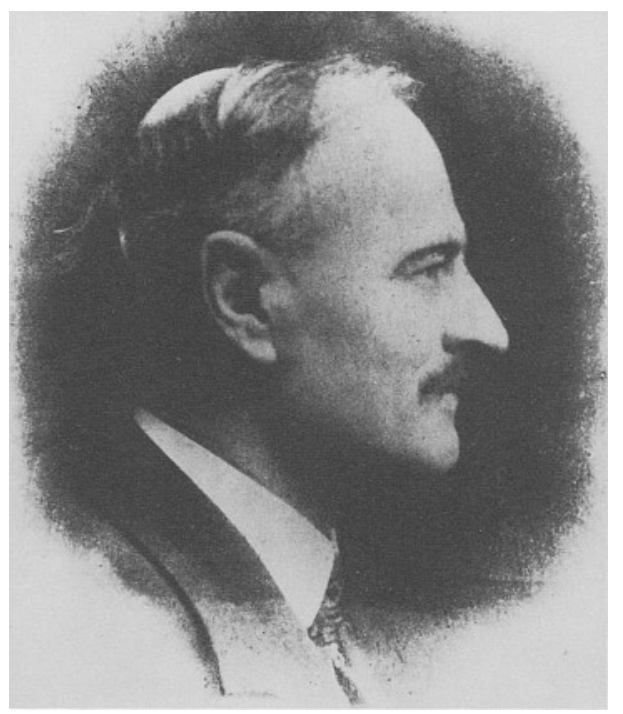

Fig. 14. Victor Henri up to serve in the 'Recherche scientifiques appliquées à la défense nationale' and took over a laboratory at the 'Ecole de Physique et Chimie' in Paris. After the French front collapsed, the laboratory received the order (12.6.1940) to move to Toulouse. Behind the retreating army, Henri, who was by now seriously ill, reached La Rochelle with his family after much difficulty and died there on 21st June 1940.

His contempories described Henri as an artistic type with irresistible charm, who did not take the normal concerns of everyday life as seriously as was expected by others: invoices were thrown unpaid into the wastepaper bin and he often did not bother to answer letters, despite this, no-one could manage to get seriously angry with him.

One of the early students of Henri was Werner Kuhn (1899-1963) who was awarded his doctorate in 1926 with a dissertation entitled 'L'équilibre chimique thermique au point de vue cinétique et photochimique'. He spent the years 1924 to 1926 with Niels Bohr in Copenhagen on a Rockefeller Fellowship. After his return he completed his habilitation in physical chemistry in summer semester 1927. He lectured on 'Absorption and Dispersion and their Relationship to Chemical Structure'. He did not lecture further because he was sent on leave. In 1928 he made his habilitation at the University of Heidelberg and worked as assistant to Freudenberg who at that time was working intensively on the empirical treatment of optical activity for the assignment of configuration. Many publications on ORD and CD measurements originate from this period. Later Kuhn became associate professor at the Technical University Karlsruhe (1930) and then full professor at the University of Kiel (1936) and Basel (1939).[83]

When Henri resigned in Zurich, Kuhn was discussed as a possible successor; however his name was not put forward by the Faculty. Hans Ritter von Halban ${ }^{[84]}$ (1877-1947) (Fig. 15), a physical chemist who originally came from inorganic chemistry was appointed instead. His dissertation, under the supervision of Werner in 1902, was on complex chemistry and entitled 'Investigations of Chromium Ammonium Compounds'. Von Halban then worked for five years with W. Ostwald and M. Le Blanc in Leipzig. He made his habilitation in 1909 at the University of Würzburg in physical chemistry. When war broke out, as an Austrian, he was called up to serve as an artillery officer initially at the front and then after sustaining serious injury, in the 'Scientific Committee for War Economy' in Vienna. In 1919 he returned to the University of Würzburg where he had been appointed associate professor in 1915 . In 1925 he became the head of research at the 'Metallgesellschaft Frankfurt a.M.'; in 
1924 he turned down a professorship at the University of Bonn but he was happy to accept the position of Henri's successor (winter semester 1930/31). With the appointment of von Halban the Institute of Physical Chemistry as an independent institute was established. In contrast to his predecessor his talents lay less in the discovery of new effects as in the perfection of measurement techniques and the careful interpretation of measured data.

Von Halban's research concentrated on: optical precision methods to determine the concentration of weak electrolytes; improvement of quantitative spectrophotometry by the introduction of noble-gas filled light-sensitive alkali cells; investigation of the dissociation equilibria and determination of dissociation constants of weak electrolytes (phenols); investigation of the phenomena of ion pair formation and ion association by means of spectroscopy; kinetics of rapid reactions in the liquid phase with a flow method; influence of solvents on reaction kinetics and on equilibria; polarography of organic substances. He worked for almost 40 years on the photoreaction of 1,1,2,2-tetrabenzoylethene, ultimately together with $\mathrm{H}$. Schmid, who had made substantial contributions to the structure determinations of individual products and received an introduction to photochemistry. [85]

To us students H. von Halban was a friendly but rather reserved person with a noble behaviour. In later years he lectured sitting down due to a heart problem. He died one week before his official retirement. During his time only twelve dissertations were completed; organic chemistry under Karrer proved to be so attractive that very few students chose physical chemistry as their specialist subject. Despite this the

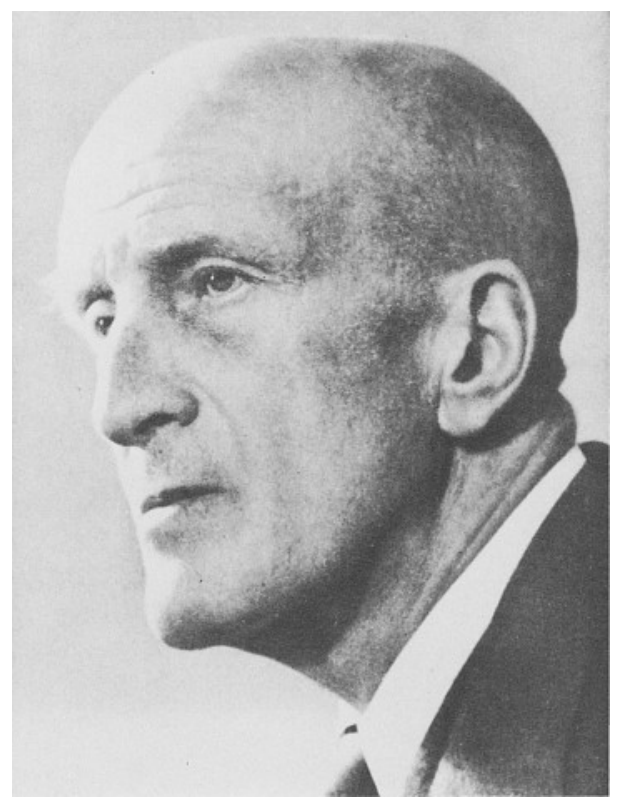

Fig. 15. Hans von Halban number of his students who subsequently became university lecturers is astonishing high: L. Ebert, J. Eisenbrand, K. Rast, G. Kortüm, B. Szigeti, K. Wieland.

In summer semester 1935 Felix Almasy made his habilitation in 'physical chemical biology' at the Faculty of Veterinary Medicine with a laboratory in the Physical Chemistry Institute. He was a student of Henri's and had been awarded his doctorate in 1933. His interests were in absorption, fluorescence and Raman spectroscopy of biologically important molecules. Karl Wieland made his habilitation in summer semester 1941. He was originally an experimental physicist who established by spectroscopy the existence of radicals in gas equilibria at $800-1200{ }^{\circ} \mathrm{C}$. He also investigated extensively the thermal transformation of azulene into naphthalene.

Klaus Clusius (1903-1963) (Fig. 16) was appointed as the successor to von Halban in winter semester 1947/48. [87] With this appointment the University gained an internationally recognised expert in thermodynamics and kinetics, who gave the somewhat sleepy Physical Chemistry Institute new impetus and quickly made it into an active and stimulating centre for modern physical chemistry research. The changes, as is often the case, were not easy for the organic chemists and I still remember the slight unease, as a former student of von Halban, with which I approached the examination in physical chemistry with Clusius whom I barely knew at the time.

Clusius gained his doctorate under the supervision of A. Eucken in Breslau in 1928, and then went as a Rockefeller Fellow to C. N. Hinshelwood in Oxford and later to W. H. Keesom in the KammerlinghOnnes Laboratory at the University of Leiden where he first came in contact with

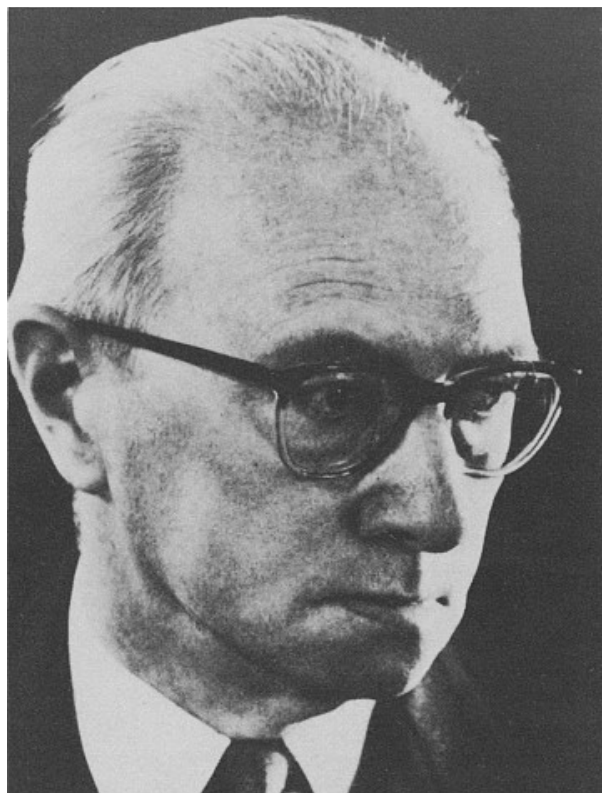

Fig. 16. Klaus Clusius low-temperature physics. In Leiden he discovered the lambda point of liquid helium. In 1930 he made his habilitation at the University of Göttingen, was appointed as associate professor in 1934 at the University of Würzburg and full professor in 1936 at the University of Munich as the successor to Kasimir Fajans.

Clusius' scientific work comprises approx. 300 publications. The contents can only be summarised briefly here: lowtemperature calorimetry, proof of the free rotation of a molecule in a solid, kinetics of chain reactions, thermodynamic measurements on $\mathrm{D}_{2}$ and $\mathrm{HD}$, determination of the nuclear spin 1 for $\mathrm{D}$, phase transitions in solid $\mathrm{CH}_{4}, \mathrm{CH}_{3} \mathrm{D}, \mathrm{CD}_{4}, \mathrm{PH}_{3}, \mathrm{SiH}_{4}, \mathrm{GeH}_{4}$, $\mathrm{H}_{2} \mathrm{~S}, \mathrm{D}_{2} \mathrm{~S}, \mathrm{H}_{2} \mathrm{Se}, \mathrm{D}_{2} \mathrm{Se}$ etc. Clusius became known for the invention of the thermodiffusion column (Trennrohr) with which gas mixtures could be separated, and in the ingenious apparatus, thermodiffusion could be multiplied to such an extent that the pure isotopes could be separated (Fig. 17). The first experiment and the one that brought Clusius international recognition was the separation of $\mathrm{H}^{35} \mathrm{Cl}$ and $\mathrm{H}^{37} \mathrm{Cl}$. Further separations of ${ }^{20} \mathrm{Ne} /{ }^{21} \mathrm{Ne} /{ }^{22} \mathrm{Ne},{ }^{84} \mathrm{Kr} /{ }^{86} \mathrm{Kr}$, ${ }^{18} \mathrm{O},{ }^{15} \mathrm{~N},{ }^{36} \mathrm{~A} /{ }^{38} \mathrm{~A},{ }^{13} \mathrm{C}$ followed. Some of these separations were enormously timeconsuming and took years. The pure isotopes were not only used for precise thermodynamic measurements but were also available for general use, e.g. ${ }^{86} \mathrm{Kr}$ was used as a new unit length measurement and to determine the age of minerals. No fewer than 40 publications were written on the production of ${ }^{15} \mathrm{~N}_{2}$ and its derivatives. The

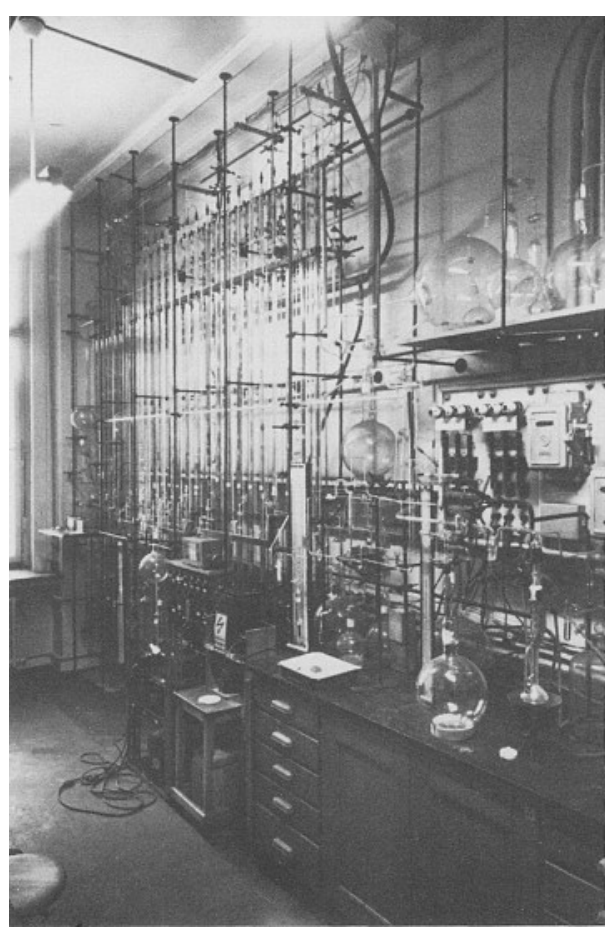

Fig. 17. Thermal diffusion columns for the separation of isotopic gases 
thermodiffusion columns were used to produce ${ }^{15} \mathrm{NH}_{3}, \mathrm{H}^{15} \mathrm{NO}_{3}, \mathrm{H}^{15} \mathrm{NO}_{2}$ and these reagents were applied for the first time for the determination of structures and reaction mechanisms. The following examples give an overview:

- In the Fischer indole synthesis from arylhydrazone (19), the hydrazone-N was cleaved as ammonia.

- The diazotisation of phenylhydrazine (21) to produce the isotopomeric phenylazides ( 22 and $\mathbf{2 3}$ ). For the interpretation a protonated three-ring derivative (triazane) was proposed.

- A linear pentazene (25) and a phenylpentazole (26) were postulated as intermediates in the synthesis of phenylazide from phenyldiazonium salt (24) and azide ions; these were later isolated.

- The linear structure of arylazides, diazomethane and diazoacetic ester was proven.

- In the synthesis of azides from sodium amide and $\mathrm{N}_{2} \mathrm{O}$, the isotopomeric azides (28 and 29) were formed, possibly via a symmetrical intermediate (Scheme 10). Clusius was a stimulating teacher and excellent speaker with great charisma. In the short time that he worked in Zurich, 35 students were awarded their doctorates. His excellent experimental skills enabled the construction of complicated apparatus such as in his famous experimental lectures with flames or liquid hydrogen. As a discussion partner he impressed with his great scientific knowledge and his broad knowledge of history. His opinion carried great weight in the Faculty. As Dean he played a decisive role in the appointment of the successor to Karrer and the reorientation of the Institute of Chemistry. Clusius received many honours: he was awarded the Cannizzaro Prize, the Marcel-Benoist Prize, the Dechema Prize and the Mario Giacomo Levi Prize. He was elected Dr. h.c. of the Technical University
Hannover and honorary member of many scientific academies.

Shortly after the death of Clusius, his coworker of many years, Kuno Schleich, completed his habilitation in the summer semester 1964. He took on the interim directorship of the Institute. His research interests were the low-temperature separation of isotopes, and calorimetry and thermoanalysis of isotopic gases. He left the University the same year and took up a post in industry.

Heinrich Labhart (1919-1977) (Fig. 18) was appointed as the successor to Clusius in winter semester 1964/65. ${ }^{[88]} \mathrm{He}$ was originally a solid-state physicist and had completed his dissertation under the supervision of G. Busch and P. Scherrer at ETH in 1947. Then he took a scientific post at the Medical Clinic of the University Hospital of the Canton of Basel where he worked on the improvement of electrophoretic separation of proteins, amongst other topics. From 1951 he worked in the physics department of Ciba in Basel. Besides that he made his habilitation at the ETH (SS 1952) and in 1954 also at the University of Basel. In 1958 he was appointed part-time associate professor at the University of Basel. He held lectures on solid-state physics and quantum chemistry. A research visit in 1956 of several months at the University of Chicago brought him into contact with theoretical chemists such as Robert Mulliken and John Platt. In 1960 he took over a new group at Ciba for dye molecular physics. His work on the optical behaviour of molecules in electric fields, which gained him wide recognition, originated from this time. He was also interested in the developments in quantum chemistry. In 1964 he received almost simultaneously offers from the Polytechnic of the University of Lausanne (EPUL) and the University of Zurich. He decided in favour of Zurich. In Zurich he

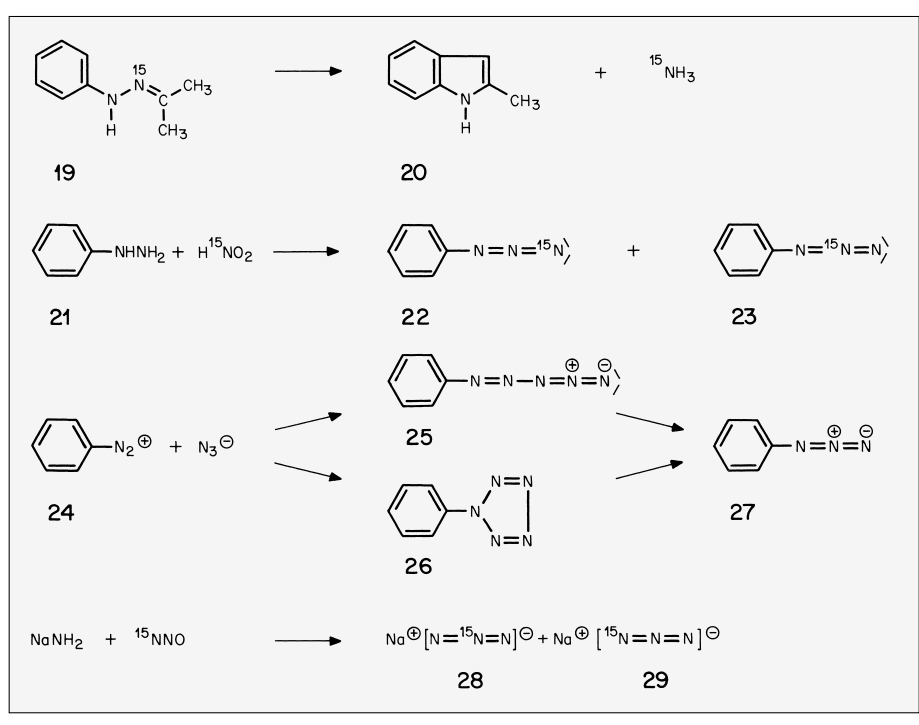

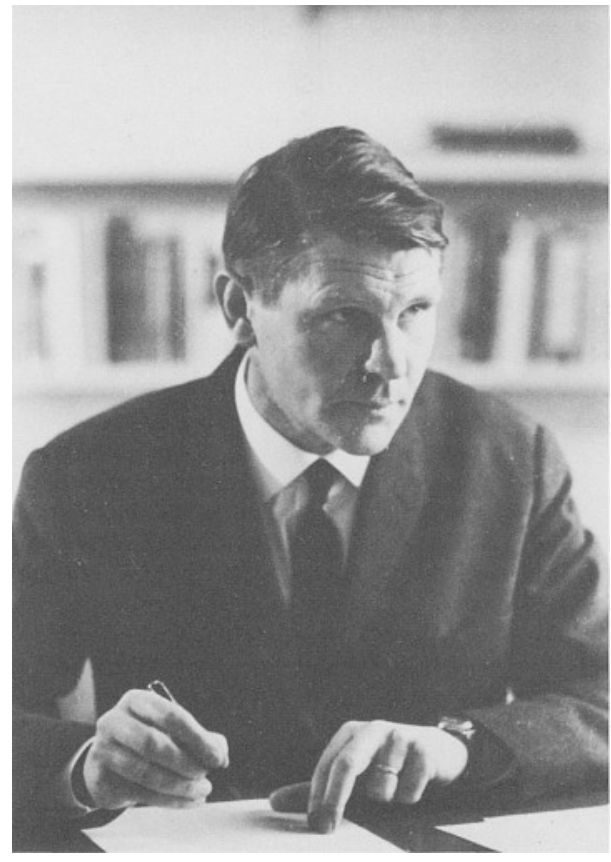

Fig. 18. Heinrich Labhart

soon gave the Institute a new direction. This was a reorientation in modern spectroscopy, which was not greeted with joy from all participants. Research concentrated on: electrochromic phenomena, determination of dipole moments of excited molecular states, the $\sigma, \pi$ interaction and the calculation of the charge distribution in heterocycles. Labhart's interests moved increasingly towards the investigation of primary photochemical processes and the complex paths that electronically excited molecules return to the ground state. Also photoreactions on aromatic heterocycles were investigated in a close collaboration with the photochemistry group of Hans Schmid.

Labhart fulfilled his duties very conscientiously. His five-volume 'Introduction to Physical Chemistry' is a sign of his teaching skills. To outsiders he always appeared reserved; he was never intrusive. His deeply friendly and cheerful nature and his wellbalanced judgement in all scientific questions made him a respected and liked colleague and teacher. It is tragic that he did not live to experience the new Physical Chemistry Institute that he had planned so intensively. But Labhart had organised the Institute in such a way that his death did not leave such a vacuum that earlier premature deaths or retirements had done.

\section{Rämistrasse 76 and the Expansion}

In Section 4 the construction of the Chemical Institute building was described. It sufficed until the beginning of the 1930s when the number of students began to increase steadily; from then on renovations proceeded at ever-decreasing intervals: 
1931 Storey added for a laboratory for medical students.

1946 Another storey added to extend the Physical Chemistry Institute.

1956 Wing of the 'Oberrealschule' (Rämistrasse 74) taken over; extension of the library.

1957/58 Renovation of the basement, construction of an intermediate floor, construction of new workshops and labs for chromatography, $\mathrm{N}_{2}$ condensation etc.

1965 Rebuilding of the inner courtyard with the construction of two underground floors.

1966 Take-over of further parts of the 'Oberrealschule', in particular for mass spectrometry labs.

1966/67 Take-over of a further wing of the 'Oberrealschule', for the extension of the Physical Chemistry Institute and the library.

Extension of the house on Schönleinstrasse 2 (Fig. 19) for the solid-state lab of the Inorganic Chemistry Institute and later for the organometallic and complex chemistry group of Prof. H. Werner.

1969 Renovation of a further wing of the 'Oberrealschule' on the 3rd floor for practical sessions in the Organic Chemistry Institute and for the Medical Laboratory.

1973/74 New living space for the janitor, the Pedagogic Institute, the Linguistic Department of the German Seminar, the language lab, the Biochemical Institute and the external station of the Computing Centre.

1979 Assignment of new rooms for the Biochemical Institute.

This short chronological summary omits the many small renovations and alterations. It shows how generously the authorities reacted to the growing number of students and the growing research requirements of the Chemical Institutes. Even when the internal planning for the new chemistry building started, necessary alterations were authorised and implemented.

After the Chemical Institutes moved out in summer 1978, the entire building was fundamentally altered. The large lecture theatre no longer exists and a former student would barely find his way around. The total floor space of $7760 \mathrm{~m}^{2}$ is now shared by one seminar and six institutes from four

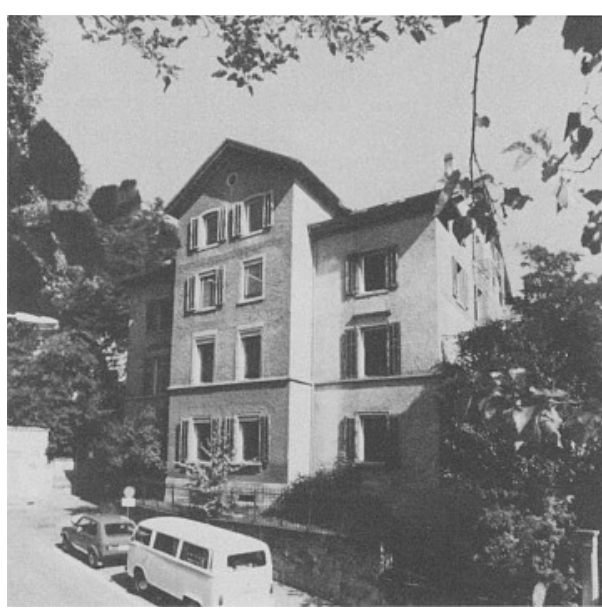

Fig. 19. Schönleinstrasse 2

Faculties: ${ }^{[89]}$ the German Seminar, the Institute for Medical Genetics, the Institute for Mathematics and Applied Mathematics, Northern Philology, Pedagogic Institute, the language lab, television services and the audiovisual department of the University. The parts of the Biochemical Institute that occupied the former 'Oberrealschule' moved together with rest of biochemistry to the Irchel.

The building on Schönleinstrasse 2 is now used by the Dentistry Institute.

\section{Inorganic Chemistry from Gerold Schwarzenbach onwards}

For chemists of the current generation as well those at the time the name of Schwarzenbach is so closely associated with the renaissance of inorganic chemistry in the German-speaking countries that many readers will react with disbelief to find out that during the entire time that Schwarzenbach was at the Institute, there was no independent Institute of Inorganic Chemistry. It has already been mentioned in Sections 8 and 9 how the lecture courses were divided amongst the professors in the Department of Physical Chemistry and the two positions of section head. After Gränacher's resignation, Gerold Schwarzenbach ${ }^{[90]}$ (Fig. 20) was appointed as his successor (1.1.1931). He had been awarded his doctorate under the supervision of W. D. Treadwell at the ETH in 1928 with a dissertation entitled 'Studies of the Salt Formation of Mordant Dyes' and then worked with W. Bradley in R. Robinson's group in Manchester and London on the synthesis of flavones and anthocyanidines. His habilitation in winter semester 1930/31 concerned 'the entire field of chemistry'. He published only one article with Karrer on the specific acidity and the structure of vitamin C. A sabbatical during the winter semester 1937/8 and summer semester 1938 allowed him to go to the Rockefeller Institute of Medical Re- search in New York as a Rockefeller Fellow to work with $\mathrm{L}$. Michaelis and then to L. Pauling in Pasadena. This stay in America had a great influence on the development of Schwarzenbach's scientific interests. Further positions followed: 1943 associate professor for analytical chemistry and 1947 full professor for "Analytical Chemistry and Special Fields of Inorganic Chemistry'. Schwarzenbach resigned on 31st March 1955 to take up the position as Treadwell's successor at the ETH.

During his 25-year activities at the University, his reputation as a scientist and teacher steadily increased. Despite this he only had contact with the students during practicals and special lectures since Karrer held the main lecture course on inorganic chemistry until his retirement. In addition most of the students were well aware that Karrer did not tend to ask questions in inorganic chemistry, neither in the written nor the oral final exams. This odd situation caused great unease both within and outside the Institute but there was no-one with the authority to persuade Karrer otherwise. Karrer - and not only he - did not seem to have recognised the objectives that Schwarzenbach was following with his extensive acidity measurements, since it appeared to be no more than a special method of physical chemistry which, even if different, had already been done by von Halban. Although Schwarzenbach's textbook of 'General and Inorganic Chemistry’ (1st edition in 1941) was greatly appreciated by the students since it put general concepts before extensive facts, it was criticised heavily by specialists for obvious and perceived errors. It should be remembered that Schwarzenbach only became known to wider circle of chemists from 1945 onwards. If Schwarzenbach had had the patience to wait for Karrer's retire-

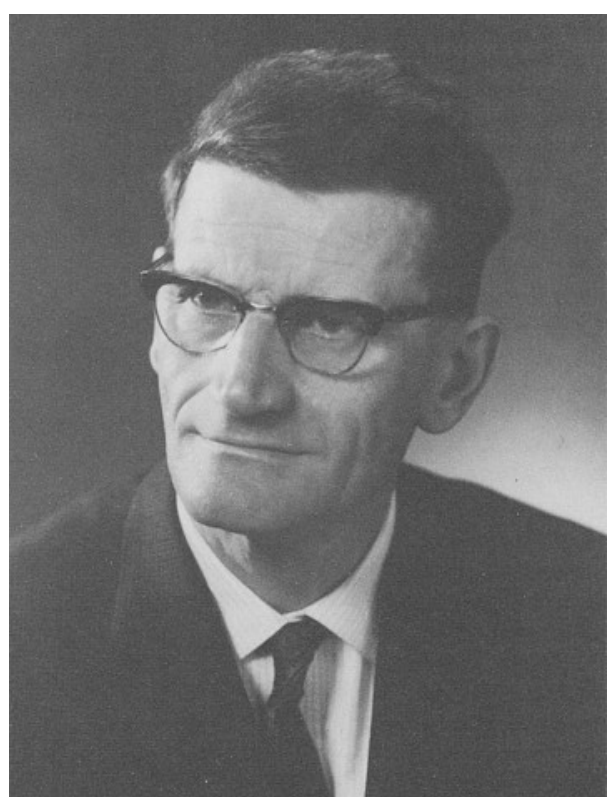

Fig. 20. Gerold Schwarzenbach 
ment, he would have certainly gained his independent Institute of Inorganic Chemistry - and would probably been the successor to Karrer as well.

Schwarzenbach's research encompassed many aspects: At the beginning he attempted to produce a modern concept for the nature of acids and bases, with contributions on substituent effects. Measurements of keto-enol equilibria with a simple flow apparatus yielded values that are still cited today. A new direction was taken when he discovered that cations can have a significant influence on the equilibrium in an investigation of a series of dyes in a wide $\mathrm{pH}$ range, and that nitrolic triacetic acid and ethylene diamine-tetraacetic acid showed a decrease in the $\mathrm{pH}$ when alkali earth cations were added. This led to investigations on metal complexes by means of potentiometric measurements. A practical analytical technique was developed with the discovery of specific metal indicators, e.g. eriochrome black T.[91]

At this time synthetic investigations also began to clarify the structural basis for the 'chelate effect' in addition to many measurements of complex formation constants. The results had a great influence on biological, biochemical, limnological and other concepts.

Schwarzenbach did not usually attempt to isolate the generally labile complexes. Despite this, to demonstrate a connection with the research of A. Werner, the structure of the chiral (!) EDTA-Ca ${ }^{2+}$-complex 30 was determined (Scheme 11).

After Schwarzenbach's move to the ETH, biological chelates such as ATP, phosphoglycerinic acid and iron-complexing antibiotics were studied. Research on protonation and deprotonation processes, salt cryoscopy and polynuclear complexes of $\mathrm{Cr}(\mathrm{III}), \mathrm{Co}(\mathrm{III})$ etc., metal sufides and aromatic complexes with $\mathrm{Hg}$ was also performed.

Schwarzenbach was very popular amongst the students. From my own time as a student, I remember well his extensive personal discussions on analytical problems. As I was interested at the time in the composition of an armoured steel, he devel-

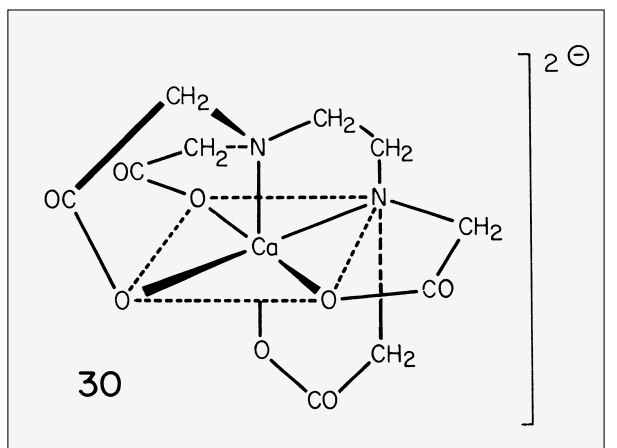

Scheme 11. oped a special analytical procedure for me. His tutorials in analytical chemistry were also popular. His dry and sometimes sarcastic comments were never insulting because one felt that an superior brain was behind it all.

In addition to his research in current scientific concepts Schwarzenbach later became interested in the history of the development of concepts in chemistry, e.g. the acid-base concept and valence theory. He received many honours: the Werner Prize of the Swiss Chemical Society (1936), the Marcel Benoist Prize (1964) and many medals; the Universities of Bern (1971) and Fribourg (1974) elected him Doctor honoris causa.

When Schwarzenbach resigned from the University, his former student W. Schneider took on the interim leadership of the analytical department, and E. Schumacher became section head. Schumacher had completed his doctorate under the supervision of $\mathrm{Clu}$ sius but then made his habilitation in analytical and inorganic chemistry in summer semester 1956. After Karrer's retirement, Schumacher was appointed as full professor and the first director of the newly created Institute of Inorganic Chemistry (winter semester 1959/60). Under his dynamic leadership, research was oriented towards physical-inorganic problems and there was an impressive increase in the instrumentation. This included rapid analysis of metal ions by means of focussed ion exchange in an electric field, construction of a mass spectrometer for many applications, geochemical research on age-determination of meteorites, fluorine chemistry and the production of noble gas fluorides. Schumacher was the first at the University of Zurich to use eidophor television projection of experiments into the large lecture theatre. His good connections to chemistry teachers at schools and his great didactic skills helped to modernise the introductory lectures.

It was a great loss for the new Inorganic Chemistry Institute when Schumacher, disappointed by the delays to his wishes for expansion, accepted an offer to become the head of research of photochemistry at Ciba (1964). ${ }^{[92]}$ In addition the appointment of his successor took so long that the further development of the Inorganic Chemistry Institute came to a complete halt. The administrative duties and the introductory lecture course were performed in the interim period by Dr. W. Ludwig (senior lecturer since winter semester 1967/68) and other lecturers from the Organic Chemistry Institute.

In 1966 Hans Rudolf Oswald was appointed as the successor to Schumacher. He received his doctorate in 1960 at the University of Bern under the supervision of Prof. W. Feitknecht with the structural chemistry of hydroxide salts of the $3 \mathrm{~d}$ transition met- als and then worked as Oberassistent and lecturer and took over the X-ray department and the electron microscopy lab. He worked as a postdoc at the Cavendish Laboratory, Cambridge, England, and in America. His habilitation in summer semester 1965 was on 'Inorganic Chemistry and in particular Solid-state Chemistry'. Crystal structure analyses of hydroxide salts, chromium(II) chloride, manganese oxide and research on topotactic reactions of hydroxide-containing phases of copper, manganese, and zinc brought him wide recognition.

In Bern Oswald left behind a very wellequipped laboratory and in Zurich not only had to rewrite the lecture courses in inorganic and analytical chemistry but also had to plan and procure the necessary infrastructure for his research. Many young chemists and technicians who had joined him from Bern were an invaluable help in this undertaking. In Zurich the emphasis was placed on the new field of 'solid-state chemistry', in particular the elucidation of relationships between structure, morphology and reactivity. At first the structural chemistry of hydroxide compounds dominated but this soon broadened to include a whole spectrum of topics, different methodology and investigated compound classes through to solid metal complexes. New possibilities were opened up by the installation of modern thermoanalytical techniques for the quantitative study of energetics, kinetics and mechanism of reactions in the solid state. X-ray techniques and electromicroscopy were also improved.

The extra space that had been needed for so long was finally provided by taking over Schönleinstrasse 2 (see Section 11). At the same time planning began for the new institute building on the Strickhof site. An important personnel and scientific improvement was achieved with the appointment of Hermut Werner as assistant professor for the beginning of winter semester 1968/69. $\mathrm{He}$ had gained his doctorate under the supervision of E.O. Fischer at the Technical University Munich in 1961, and took a postdoc position at the California Institute of Technology, Pasadena, followed by habilitation at the TU Munich.

Werner began a successful series of investigations on the preparative synthesis of complexes of transition metals, in particular those with sandwich structures, the kinetics and mechanism of substitution reactions of organometallic complexes, reactivity of complexes with electron-rich metal ions and insertion reactions of metal-hydride, aryl and alkyl complexes. In a certain sense this research could be considered a contemporary continuation of the early complex chemistry of A. Werner. H. Werner was promoted to full professor already in 1970 . He was active in the restructuring of the lecture courses. In winter semester 1975/76, to the 
great regret of colleagues and the Faculty, he took up the offer of a professorship at the University of Würzburg.

In summer semester 1970 A. Wyttenbach completed his habilitation in radiochemistry and a year later R. Grauer completed his in inorganic chemistry. Both took over lecture courses as external lecturers. They were followed by J. R. Günter (winter semester 1976/77), E. Dubler (summer semester 1977), S. Veptek (winter semester 1977/78); all three in inorganic chemistry and working full time at the Institute.

J. H. Ammeter was appointed successor to $H$. Werner in winter semester 1978/79. He is a representative of theoretical-coordination chemistry and spectroscopy. In winter semester 1982/83 A. Salzer completed his habilitation in coordination chemistry.

\section{Organic Chemistry under the Leadership of Hans Schmid}

After Karrer's retirement and after the 'division' of the Institute of Chemistry, Hans Eduard Schmid (1917-1976) became the first Director of the Institute of Organic Chemistry in winter semester 1959/60. At this time Schmid already had his own active group of doctoral students. In addition to Schmid, also with their own research groups, were M. Viscontini (associate professor since winter semester 1947/48), R. Schwyzer, A. S. Dreiding and C. H. Eugster (both senior lecturers since summer semester 1955).

H. Schmid (Fig. 21) was born in Hendschiken $A G,{ }^{[93]}$ but moved with his parents at nine years of age to Vienna and went to school there. He completed his studies in

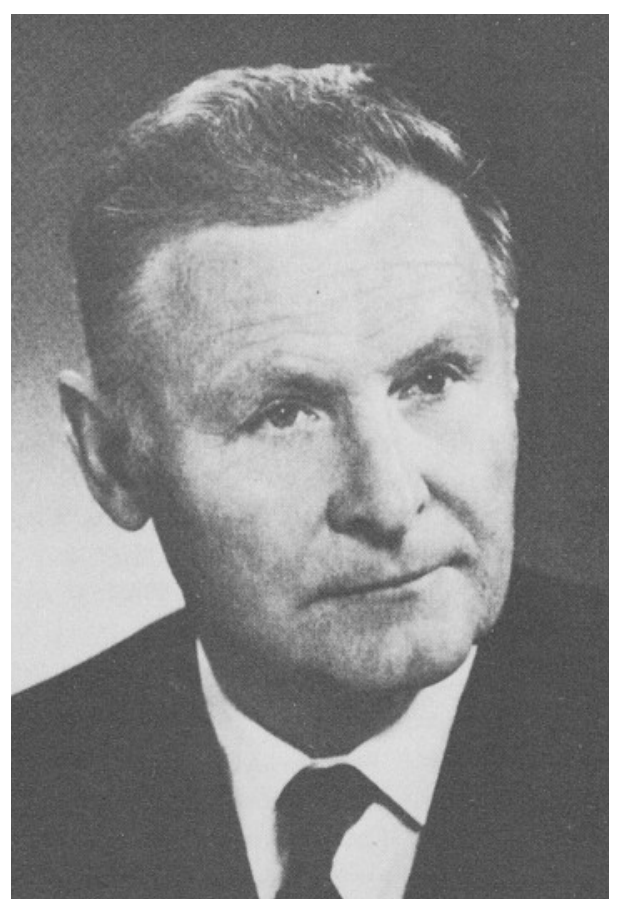

Fig. 21. Hans Eduard Schmid chemistry at the II. Chemical Institute of the University of Vienna in 1941 with a dissertation under supervision of E. Späth on the structure determination of natural cumarins and dimeric aldol. His teachers were F. Feigl, C. Mayr, F. v. Wessely, H. Mark and E. Späth. After returning to Switzerland in 1942 he became assistant and then senior research assistant to Karrer. In winter semester 1944/45 he completed his habilitation which was entitled 'The Current State of Biotin Research and Synthetic Experiments in the Biotin Series'.

Impressed by the rapid expansion of organic chemistry since the end of the Second World War and the greatly increased number of students, Karrer decided to expand the small number of lecturers: $\mathrm{H}$. Schmid and M. Viscontini were appointed simultaneously as associate professors and section leaders.

A research visit to $M$. Calvin in Berkeley (1949), who was working at the time on $\mathrm{CO}_{2}$-fixation in algae, introduced Schmid to the ${ }^{14} \mathrm{C}$-technique. Later back in Zurich he developed the technique to a successful method for the investigation of reaction mechanism and biogenesis sequencing. Many of his former students in this field were influential in introducing isotope laboratories in many chemical companies.

When Schmid succeeded Karrer in Organic Chemistry, ${ }^{[94]}$ he was able to calm and settle the unavoidable tensions that had arisen with such a far-reaching change. $\mathrm{He}$ often sought advice from his colleagues and their agreement in important reforms. $\mathrm{He}$ attempted consciously to replace the aura of respect that had surrounded Karrer with a more natural approach to colleagues and students. He also worked with great success to improve the somewhat strained relationship between Chemistry at the ETH and the University.

Further improvements were made to the organisation and structure of the teaching; the Saturday seminar was introduced and the colloquia were reactivated. In the research fields a careful and gradual expansion was targeted, which was strongly tailored to continuity and which showed no break with the past. Schmid also modernised the instrumentation and supervised many renovations on the building and broadened the technical services.

Before his appointment as director, Schmid had already done much to improve the general laboratory skills in the Institute and e.g. had brought along a valuable bulb tube distillation method from Vienna and improved it in Zurich. He had good skills in microtechniques for isolation and purification of compounds and he often in later years demonstrated his experimental abilities in laboratory courses. In this connection it is surprising to learn that although he was one of the main initiators of the intro- duction of modern spectrometry, he never made the effort to learn to use the instruments so that he could measure a spectrum himself. He always left the measurements to his coworkers.

Schmid was a talented but not conventionally brilliant lecturer. His lectures were impressive due to their content, clear structure and the conviction with which he conveyed the material to his students. The lectures never became routine, Schmid continually incorporated new results and modern concepts. During the entire time of his professorship he worked on improving his lecturing techniques and the content and in doing so gained many PhD students from the undergraduates attending his lectures. In the specialist lecture courses and later in the postgraduate courses assigned to him, Schmid used the courses as an opportunity to read into a new field of study, in which he quickly succeeded thank to his ability to rapidly understand and assimilate new material. I consider it a great honour to have been invited to share the introductory lecture course with him. Schmid's ability to encourage the scientific development of his coworkers and to motivate them to high performances was always admired by his colleagues. His research group was known for its strong and cohesive work ethic.

Schmid initially concentrated on the isolation and structure of complex natural products, both from preference and as a result of his training in Vienna - disregarding the unsuccessful attempts to synthesise biotin. He was barely interested in the organisms that produced the substances. For many years Schmid carried out experiments himself. In doing so he became an absolute expert. Many structures that were determined at the time principally from interpretation of clever degradation experiments can be considered as some of the best natural product chemistry. They required, in addition to observational skill and experimental ability, a great deal of hard work on behalf of the chemist involved. Schmid therefore was always careful to staff his research group with motivated people. For this reason he never gave up control over the teaching courses that allowed him to judge the qualities of up-and-coming students. These courses were, in particular, the preparative organic practical and the distribution of the Literaturpräparat (which were often connected with a particular problem of one of his assistants) and the Hausprüfung that every practical student had to perform for him once he had satisfactorily completed one or more trial exams for a coworker. Schmid also retained responsibility for distributing the assistant positions. For many years the budget was used almost exclusively in his own research group, and it required energetic intervention by the disadvantaged lecturers to the Erziehungsdirektion to 
change this situation somewhat to their advantage.

In later years Schmid's research interests turned more and more to demanding mechanistic concepts although the experimental work was never neglected. All the work that came out of his group is understandable down to the last detail.

The scientific work is contained in approx. 480 publications. These show not only a wide range of topics but also a high information content. Schmid enjoyed following different aims simultaneously and independently. The main interests were: natural dyes, mechanistic studies, and photochemistry. Here only a brief description is possible. ${ }^{[95]}$

The suggestion to work on the curare alkaloids, particularly the so-called calebasse type, came from Karrer. In an impressive series of articles, which continued after Schmid's death, this chemistry developed into an excellent example of what natural product chemistry was capable of at that time. ${ }^{[96]}$ The curare project was started as a one-man project, but expanded continually until it occupied one of the biggest research groups in the Institute in which some of the most capable chemists worked. One should not forget the background work that made this success at all possible: the acquisition of the many curare samples from South America, the construction of suitable chromatographic systems ${ }^{[97]}$ and continuous improvement of the spectroscopic methods. In 1956 it was shown that $\mathrm{C}_{40}$ alkaloids, i.e. dimers were present. In 1958 the relationship with indoles and in particular with strychnine was demonstrated. ${ }^{\text {[98] }}$ Subsequently one structure after another was presented. One of the particularly impressive results was the determination of the structure of the alkaloid villalstonine by means of degradation reactions and spectroscopy (1965). However almost simultaneously the Americans Nordman and Kumra were able to determine the complete stereostructure by means of X-ray structure analysis.

Less spectacular but for many natural product chemists no less significant were the structure determinations of fluvoplumierine (1953) and plumieride (1958). They were the first examples of structures from a large group of substances known today as the iridoids. Later it became clear that the glucosides aucubine and verbenaline, that had been investigated much earlier but not particularly successfully by Karrer and Salomon, also belonged to this group. The biogenetic relationship between the iridoids and the indole alkaloids was shown by R. Thomas (1961), E. Wenkert (1962) and others. It is strange that the Zurich group, having investigated both basis units, failed to recognise that they belonged together.

The mechanistic research of Schmid and coworkers concerned principally the exact determination of the process of molecular transformation. They have become significant for theoretical chemistry but are not easily explained in a brief review. Schmid used the ${ }^{14} \mathrm{C}$-labelling technique to tag the migrating groups of atoms, which of course required a careful synthesis and degradation plan. Key points of this research were: Proof of the intramolecular nature of the Claisen rearrangement of allyl phenyl ethers; proof of the existence of reactive intermediates by trapping reactions; explanation of the mechanism of the anomalous Claisen rearrangement; discovery of the sigmatropic $[3 \mathrm{~s}, 4 \mathrm{~s}]$ and $[5 \mathrm{~s}, 5 \mathrm{~s}]$ rearrangement; intramolecular Diels-Alder cycloadditions with rearrangement of aryl propargyl ethers and their acid-catalysed rearrangement to give tropylium salts.

The photochemical research originated in a collaboration with von Halban on the photochemistry of tetrabenzoyl ethene (see Section 10). Later it was shown that some curare alkaloids were photolabile and transformed to other compounds that could also be isolated from calebasses. Closer examination revealed that irradiation of heterocycles with $\mathrm{C}-\mathrm{N}$ double bonds not only resulted in oxidation but also reduction or that they bound to solvent molecules, e.g. methanol. This opened up a new field for Schmid of photochemical reactions in organic chemistry. Soon his research group had discovered reciprocal rearrangement of heterocycles with two hetero-atoms under irradiation, such as the transformation of pyrazoles into imidazoles, or isoxazoles into oxazoles etc. Also the strained small-ring systems such as the azirines, whose multiple ground-state reactions were investigated principally by $\mathrm{H}$. Heimgartner, became accessible through new and surprising photoreactions. They could be transformed into highly reactive ring-opened nitrile ylides which readily underwent addition to double bonds. This opened the way to new five-ring heterocycles.

In 1964 Hans Schmid suffered his first heart attack, from which he rapidly recovered. Although he gave up his heavy smoking completely, his work rate could not be curbed. To others it became clear that after this time he became more irritable and distrustful of some things which were not immediately in connection with his own interests. His restlessness increased and the remark "No time! No time!" was often heard when he wanted to avoid a problem that did not suit him. He also pointed out that he had to slow down when he wanted to protect himself from demands that he did not want to accept. He must have suspected that his time was limited. Despite this he did not reduce his workload even outside his research group: He remained director of the property Rämistrasse 74/76, president of the Widows, Orphans and Pension Fund of the University Professors, committee member and president of the Swiss Chemical Society, president of the Swiss Committee for Chemistry etc.

Schmid loved to give lectures in other countries; however the preparations and the inclusion of the most recent results in the lectures caused considerable agitation in himself and others so that he frequently returned from such congresses both exhausted and stimulated. Schmid was a popular discussion partner for the many visiting scientists at the Institute. When the planning began for the new building on the Irchel he came under additional pressure that he was able to reduce by delegation of individual tasks to colleagues so that the deadlines were able to be kept.

He was also depressed by the continually increasing number of publications in many different fields of chemistry that he wanted to follow in detail - no one from that time can forget how he left the Institute every evening with a briefcase filled with work.

$\mathrm{He}$ became increasingly concerned by the declining number of chemistry students and he was always occupied with finding measures to counter this phenomenon.

The final fatal heart attack on 19th December 1976 struck a scientist and colleague who had not yet reached the peak of his abilities.

Hans Schmid left behind 35 coworkers whose personal, scientific and financial problems were dealt with care, patience and not inconsiderable additional work by the remaining colleagues and in collaboration with Prof. Hansen (Fribourg).

After his death a collective Directorship was created and the section leader positions were discontinued.

\section{Winterthurerstrasse 190}

The construction and the operational design of the former 'Chemical Institute' on the Rämistrasse 76 were based on a low degree of specialisation, which was appropriate for the level of experimental chemistry of the time. With the increase in instrumentation, more and more dedicated rooms were required. In addition there were an increased number of chemistry majors and particularly students studying chemistry as a subsidiary subject and the increasingly urgent requirements of the Institute of Inorganic Chemistry for a modern laboratory. Section 11 describes how the authorities reacted to the wishes of the lecturers for improved working space. However it became increasingly obvious that the University had to undergo a fundamental expansion.

In spring 1960, the space requirements of Chemistry were clarified under order of the Erziehungsdirektion. These formed the basis of an internal report to the Cantonal Government on the expansion of the Uni- 
versity. The government invited the Erziehungsdirektion to produce a general spacerequirement plan. The corresponding order to the Institute directors from Erziehungsdirektor Dr. W. König is dated 13th March 1961. He demanded unequivocally that the work be accelerated. In the same year the governmental Planning Committee started work. They came to the conclusion, as is well known, that the only suitable location for the new buildings was the site of the 'Strickhof Agricultural College' in the Oberstrasse quarter. It is less than three kilometres from the main University buildings and directly neighbouring to the Faculty of Veterinary Medicine. A competition for ideas was launched for architects both in Switzerland and abroad in July 1965. ${ }^{[99]}$

The referendum of 14th March 1971, in which the partial relocation of the University together with a budget of 600 million sFr. was voted on, resulted in an unexpectedly high number of votes in favour. It was the second Cantonal referendum in which the women of Zurich had been able to participate.

Then followed a period of intensive planning, in which all lecturers and senior research assistants were involved. The successful planning was thanks to a large extent to the efforts of Dr. W. Frei, a former senior research assistant.

Delays in the completion of the unusually large construction project (Fig. 22 and 23) resulted from the late relocation of the Agricultural College, which forced a mirroring of the location of the Institute buildings along the main axis. The foundation stone was laid for the first stage on 7th December 1973. A backlog in construction due to the economic crisis and additional changes to the occupation plan of the Institute buildings ${ }^{[101]}$ made those involved doubt whether the proposed date for moving was at all possible; but Erziehungsdirektor Dr. A. Gilgen adhered single-mindedly to the timetable. The relocation of the large instruments began directly after the end of the winter semester $1977 / 78$; the summer semester 1978 was spent under reduced working conditions in Rämistrasse 76 and then the Institutes moved one after another according to a internal plan for the individual research groups. Punctually for the start of the new semester, the lectures began in the new lecture theatres, but not without a great deal of agitation for the lecturers involved. In contrast to the occupation of the new institute on Rämistrasse 76 (see p. 80) the professors, coworkers and students took over their new laboratories in a matter-offact manner and without any sort of celebrations. The reasons for this sober behaviour were probably a result of many factors: two professors who had put great effort into the planning of the new institute $(H$. Schmid and H. Labhart) had died in the past two years; the Zeitgeist and the lack of a student chemistry society that identified itself with chemistry as closely as in earlier times; the modern purpose-built architecture and the new operational concept that replaced the old definition of an institution with clearly defined sections.

Objectively, it must be said that chemistry has gained excellently equipped rooms for teaching and research; there are more than $20,000 \mathrm{~m}^{2}$ of space available, not counting the lecture theatres and the public areas. The increase in the number of research places compared to the old building varies: in the Institute of Organic Chemistry there is not much difference. Much improved are number of dedicated rooms for specialist use and the vast improvement in infrastructure. Generous equipment budgets allowed the instrumentation to be mod- ernised. The total amount spent on the first stage of the University relocation was about 250 million $\mathrm{sFr} .{ }^{[102]}$

Without doubt, the new building on the Irchel site provides Chemistry with a material foundation upon which it can develop for the good of our country and for the benefit of science.

It was therefore with concern that the lecturers have observed over many years the decline in the number of students choosing chemistry as their major subject. There are many factors to this and these have been discussed frequently. The teaching staff take any well-grounded criticism seriously and attempt to improve the teaching and to offer new research fields. Chemistry as a science has always been associated with the investigation of the material basis of life and will remain part of our culture and civilisation. We hope that the recovery that has already occurred in other countries, will also reach our country soon.

\section{Looking Back and Forwards}

\section{The Chemistry Institute on the Threshold of the 150th Anniversary}

In his retrospective ${ }^{[103]}$ on the occasion of the 200th anniversary of the Naturforschende Gesellschaft in Zurich in 1946, P. Karrer stated: "In the last century and particularly the past 60 years, chemical research in Zurich has reached a level and demonstrated achievements that far exceeds what could be expected for a medium-sized University town. Fundamental discoveries in our science will always be associated with the name of our town... The high standard of chemical research from the two academic institutions in our town forms a significant part of the foundation upon which a success-

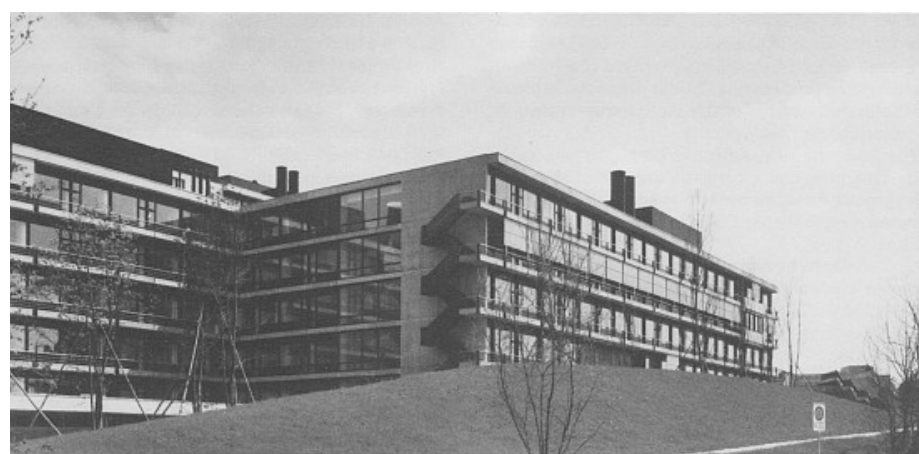

Fig. 22. Winterthurerstrasse 190; part of buildings 32 (left) and 11 (right)

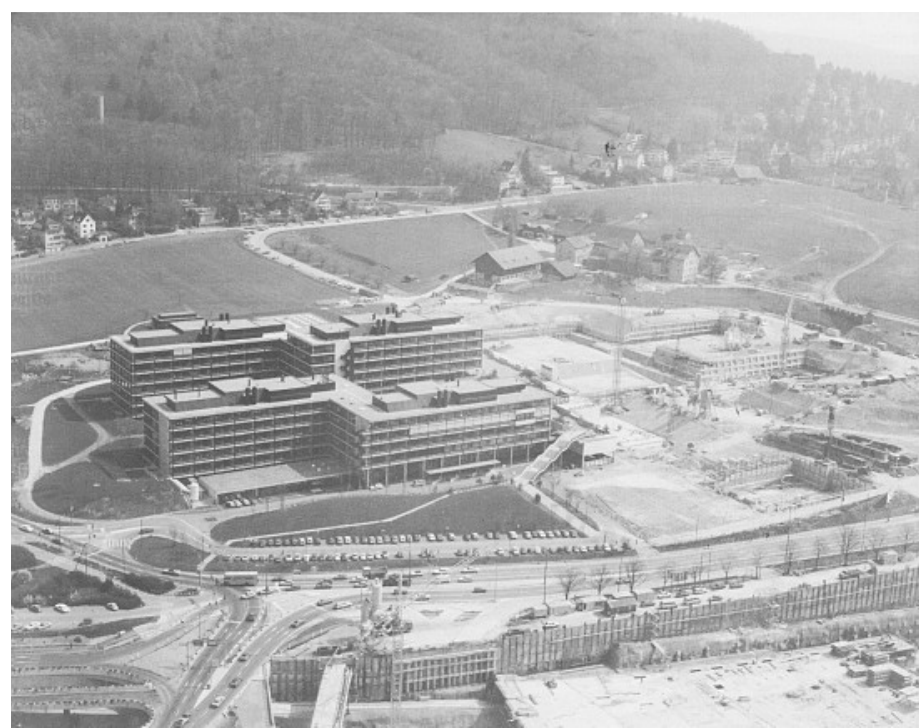

Fig. 23. Overhead view of the University of Zurich Irchel, first stage (photo by Swissair) 


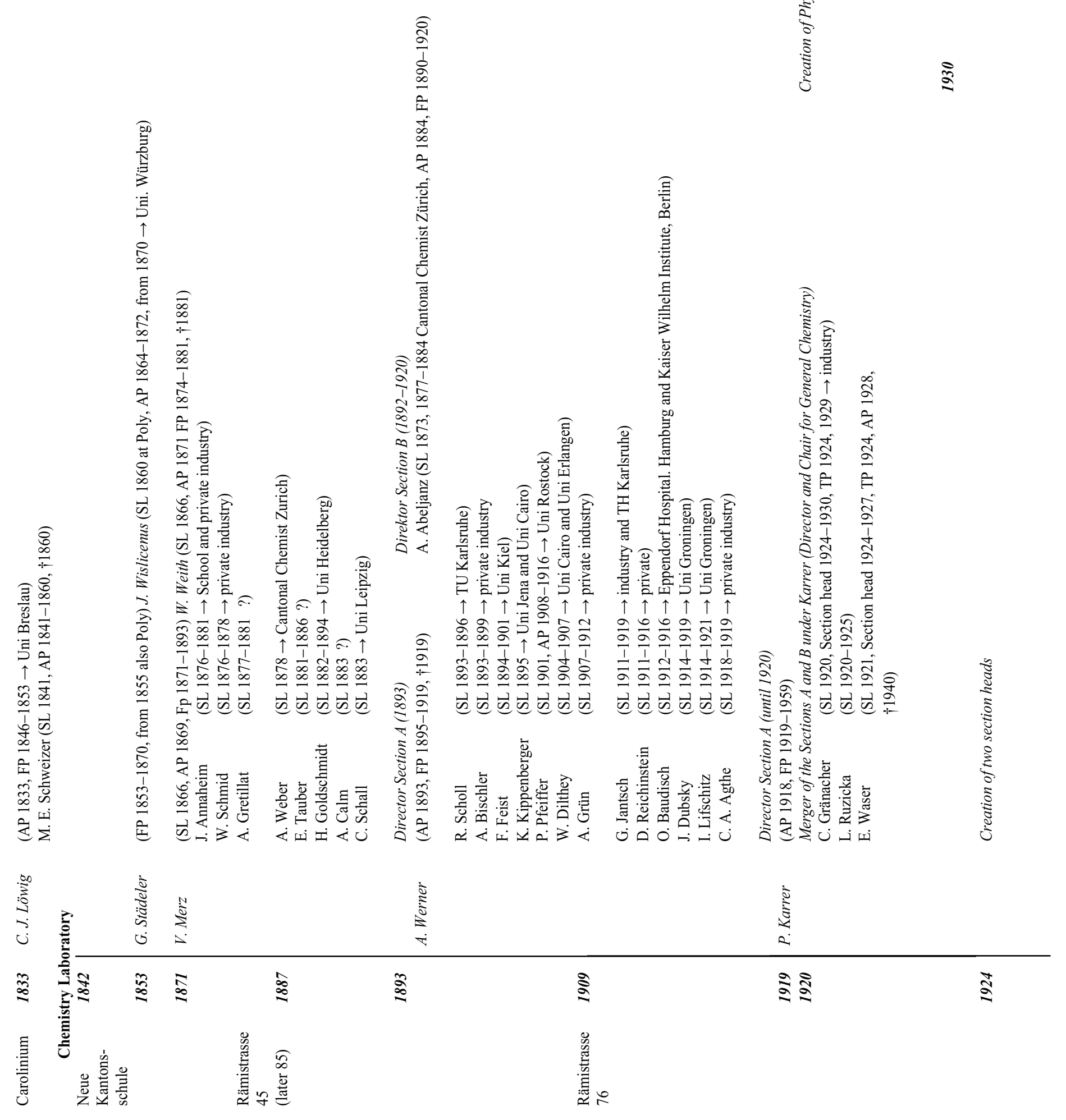



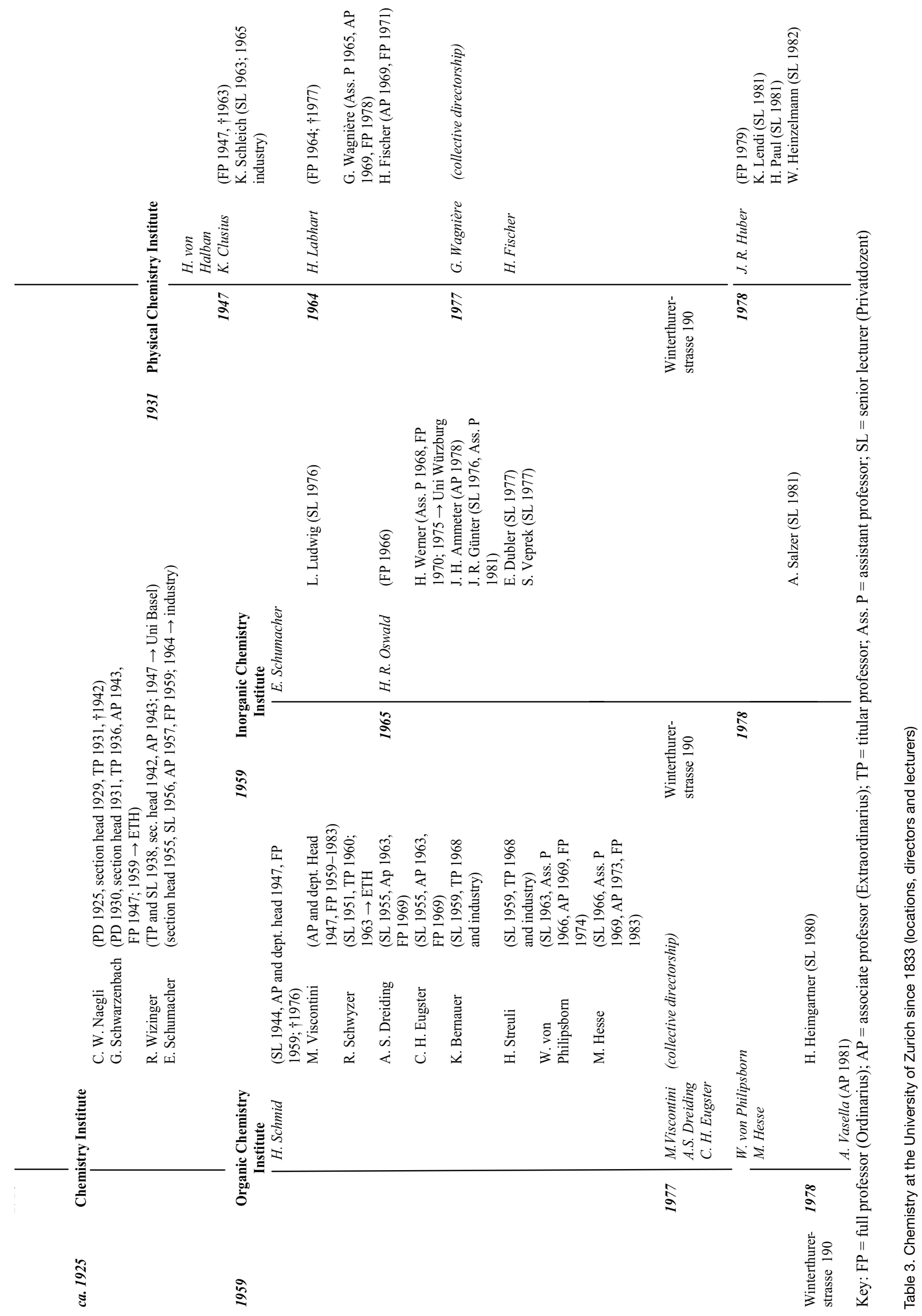
ful Swiss chemical industry could be built, and that is something that also benefits society." With this statement he was thinking of the achievements of both Chemistry Institutes at the University and the ETH. But it is also obvious in his speech that the contribution of the University is anything but minor. However today we can expand Karrer's viewpoint somewhat: Since the establishment of a 'Chemistry Laboratory' more than 1200 dissertations in chemistry have been completed, the first in 1847 . [104,105] Without doubt many of the graduates have entered various chemical industries, but also a considerable number have sought other fields of work, for example: patent law, food control, hygiene, medical laboratory, international organisations, trade, schools etc. ${ }^{[106]}$ During the time of Werner and Karrer, teacher training was relatively neglected. It has been strongly encouraged since then.

Let us also not forget the international collaborations, not only through the media of publications and congresses, but also by visiting foreign students that have spent one or two years as postdocs in the Chemistry Institutes. Many of these have returned to their homes as our friends. The textbooks written by our lecturers have contributed much to the transfer of knowledge. Let us also not forget the influence that chemistry has in other areas of University life: the training of apprentice laboratory technicians who carry out their training working together with assistants and $\mathrm{PhD}$ students; many of these young people were inspired to further their studies at a polytechnic. The number of services that the members of the Chemistry Institutes provide to the programmes in medicine, biochemistry, biology, teacher training, etc. is also significant. So many structural and analytical chemistry concepts have been integrated into the fields of medicine and science that a basic chemistry training remains a necessity.

When we, on the threshold of the 150th anniversary, think back with great pleasure and justifiable pride over the achievements of the Chemistry Institute of the University since its foundation, we also have to acknowledge how much was due to the great commitment of our predecessors, the professors and their coworkers. We include in this acknowledgement also the authorities which provided and expanded the basis upon which Chemistry was able to grow and prosper.

An overview of all the lecturers that have lectured in chemistry since the foundation of the University is given in Table 3 . For reasons of space it is not possible to include the current members of the three Institutes, however for completion a brief listing of their fields of research is given below.

\section{Institute of Inorganic Chemistry}

\section{H. R. Oswald}

Research in solid-state chemistry with emphasis on the relationship between the crystal structure and the morphology of solid materials on the one hand and chemical reactivity on the other. This requires the combined use of precise X-ray structure determination, light and electron microscopy, and in particular highly sensitive quantitative thermoanalysis and mass spectrometry. This enables kinetic reaction processes in small crystals and powders to be observed and mechanistic interpretations on the atomic level to be proposed. In addition to the 'classical' solid-state systems (e.g. hydrate salts, hydroxides) coordination compounds of metals are investigated. The research partially presents models but also depends on the requirements of applied chemistry, e.g. thermochromism or improvement of the production of catalysts from suitable precursors.

Further interests include crystal growth of substances for other research using a range of methods and the study of certain solid-solid phase transformations (cooperative Jahn-Teller effect in oxide systems and complexes).

\section{J. H. Ammeter}

Description and rationalisation of rearrangements on the electronic level and the measurement of the electronic structure of electronically and stereochemically labile metal complexes with modern spectroscopic techniques and quantum chemical model calculations.

\section{W. Ludwig}

Preparation and investigation of complexes. In addition to preparative work and spectroscopic structure investigations, the identification of the lowest electronic states in inorganic chromophores is a major field of research in the group.

\section{J. R. Günter}

Topotaxis; chemical electron microscopy. At the heart of this research is the relationship between reagent and final product in the reactions of solids. The field of topotaxis is concerned with the crystallographic-structural orientation of several phases simultaneously. High-resolution electron microscopy is used to investigate the micromorphology of multiphase reaction products, i.e. the spatial distribution, intergrowths and the structural relationships between the product phases that result from a single phase reactant. Such results are applicable in metallurgy, ceramics and materials science, mineralogy and heterogeneous catalysis.

\section{E. Dubler}

Solid-state chemistry aspects of bioorganic chemistry: Using the experimental methods of solid-state chemistry (X-ray analysis, thermal analysis, electron microscopy) substances in pathological biogenic solids such as gall stones, kidney stones or joint depositions are investigated. Temperature-dependent phase transformations, which occur for example in cholesterol have been observed and the proof of oriented growth of individual crystalline phases on other biogenic crystals (epitaxis).

In addition metal complexes with biologically significant ligands such as uric acid or sulfur-containing amino acids are synthesised and characterised.

\section{S. Veprek}

Plasma chemistry, in particular solidgas reactions in electric discharges; plasma chemical evaporation and deposition; surface chemistry, preparation and characterisation of amorphous semiconductors and dielectrics. Restoration of antique metallic objects.

Photoelectron spectroscopy, mass spectrometry, thermogravimetric analysis.

\section{A. Salzer}

Investigation of the structure and dynamics of binuclear metal complexes with organic bridging ligands. Study of nucleophilic and electrophilic addition reactions, in particular stereo- and regiospecific $\mathrm{C}-\mathrm{C}$ bonding on metal-coordinated di- and oligoolefins.

\section{Institute of Organic Chemistry[107]}

\section{Viscontini}

Metabolism of microorganisms (biogenesis of proferrorosamine from $\mathrm{Pseu}$ domonas roseus fluorescens and a blue dye from Bacillus mesenterius niger); synthesis of pyrrolizidin alkaloids; pteridine chemistry: synthesis of L-biopterine, tetrahydroL-biopterine, tetrahydro-L-folic acid and derivatives. Tetrahydro-L-biopterine is the coenzyme of the enzymatic hydroxylation of the phenyl ring in L-tyrosine, L-DOPA etc. Biogenesis defects in humans result in atypical phenylketonuria, endogenic Parkinson's disease, endogenic depression and certain forms of schizophrenia. The illnesses can be treated with oral doses of tetrahydro-L-biopterine.

\section{A. Dreiding}

The aim of our research is the development of simple model representations to interpret the behaviour of material in its many forms, also in biological systems. We study: components of plants and insects to discover new biosynthetic processes; synthesis of selected substances to characterise their 
properties as chemical communication devices, drugs, dyes and as physical measurement devices; the use of energy-rich building units for the synthesis of strained systems; the application of chemical symmetry principles to increase selectivity in targeted reactions; the transferability of tried and trusted structural and mechanistic concepts in carbon chemistry to nitrogen systems; development of mathematical models to describe and handle model structures.

\section{H. Eugster}

Natural product chemistry (glandular substances from leaf glands of African labiates; dyes from russula mushrooms, isolation and structure analysis of carotenoids), separation techniques (high-performance liquid chromatography for the separation of complex mixtures of carotenoids) stereochemistry of carotene epoxides, synthesis (O-, N-, S-heterocycles, optically active synthons for polyene synthesis, models for CD studies), Biosynthesis of cyclic carotenes.

\section{W. v. Philipsborn}

Research into preparative, structural and physical aspects of organometallic compounds. Emphasis on the application and development of high-resolution NMR methods to problems on the border between organic and inorganic chemistry. Projects: Synthesis of single and multi-nuclear olefin complexes, of transition metal clusters in the gas-phase; one and two-dimensional NMR of organic compounds; use of ${ }^{15} \mathrm{~N}$ NMR on organic chemical structure problems and biochemical problems.

\section{Hesse}

At the centre of our research activities are investigations (isolation, structure analysis) of natural products (particularly indole-, spermidine-, and spermine alkaloids) and their relevance as chemotaxonomic indicators, and the synthesis of macrocycles (lactames, lactones, carbocycles) by means of ring expansion reactions of smaller carbocycles (zip-reaction).

\section{A. Vasella}

Carbohydrates and their use as starting materials for the preparation of other natural products (nucleosides, antibiotics, amino acids, phosphone acid, enzyme inhibitors). New methods for the asymmetric induction in connection with the anomeric effect. Novel nitrosugars are synthesised and used to investigate preparatively useful methods and the production of rare sugars (amino sugars, neuraminic acids). Methods for glycoside synthesis and the synthesis of complex carbohydrates have been initiated.

\section{H. Heimgartner}

Research interests include: mechanisms of thermal and photochemical reactions of small rings; preparation of metal complexes; use of $2 \mathrm{H}$-azirines and 1-azetines for the synthesis of nitrogen-containing heterocycles. Synthesis of medium and large rings by ring-expansion and ring-closure reactions. Photochemistry of heterocycles; production of reactive intermediates; regioand site-selective 1,3-dipolar cycloaddition of nitrilium betaines. Synthesis and rearrangement reactions of sulfur-containing heterocycles.

\section{Institute of Physical Chemistry}

\section{H. Fischer and H. Paul}

Free radicals. In many chemical processes, including the primary processes of plant photosynthesis, reactions in the earth's atmosphere and technically important processes in polymer production and paint hardening, free radicals appear as short-lived intermediates. They are molecular fragments with a free electron that is not part of a bond. Due to their specific magnetic properties it is possible to observe and identify these particles during the reaction using physico-chemical methods, and to determine the mechanism and rate of reaction. Methods used include ESR, NMR, myon spin rotation and optical spectroscopy, with modern computer technology to control the equipment and analyse the data.

\section{G. Wagnière}

The natural and magnetic-field induced optical activity of molecules are measured and interpreted with quantum mechanics. The methods used include circular dichroism (CD), magnetic circular dichroism (MCD), circular polarised luminescence (CPL) and fluorescence detected circular dichroism (FDCD). The principle interest is in organic molecules, particularly those of biological significance. In addition theoretical studies on the new magnetooptical and non-linear optical effects are undertaken. The aim is the application of modern non-linear optics as a molecular spectroscopy method.

\section{J. H. Huber}

Research includes: molecular dynamics (energy absorption, energy distribution, relaxation), laser spectroscopy of molecules in molecular beams and in matrices, and investigations of light-induced chemical processes.

\section{K. Lendi}

In the framework of a general theory of irreversible processes, theoretical predication of new effects in polyatomic molecules are developed, such as quantum oscillation (beats) or magnetic resonance phenomena in chemically reacting systems.

\section{Acknowledgments}

I would like to thank all my colleagues in the Chemical Institutes for discussions and contributions, Frau B. Leissing (secretary of the Dean of Phil. Fac. II) and G. Graglia and A. Schumacher (Chancellery archives) for help in obtaining the documents. This publication was made possible by a generous contribution from the 'Dr. Emil Bindschedler Foundation in memory of Prof. Dr. A. Werner'. I thank the many people and institutions for the willingness to provide me with photographs.

General comment: The personnel dossiers come from the University Archives and the Public Record Office of the Canton of Zurich. Requests to the University Archives

[1] The 'Carolinum', former convent school of the 'Grossmunster'; the new building on what is today Kirchgasse 9, is now occupied by the Theological Faculty of the University of Zurich.

[2] Löwig discovered bromine somewhat later but independently of Balard.

[3] Festschrift 'Die Universität Zürich 1833-1933 und ihre Vorläufer', E. Gagliardi, H. Nabholz, J. Strohl, Zurich, 1938.

[4] His books were carefully kept in the library of the Chemistry Institute as objects of great value. Löwig had taught before and for some time after his appointment as associate professor at the 'Industry School', a school of further education for the technical professions. One of his students from Easter 1833 onwards was Gottfried Keller, whom he continued to act as mentor, for example in his recommendation to the Erziehungsand Regierungsrat for the stipend in 1848 . [5]

[5] E. Ermatinger, 'Gottfried Kellers Leben', Artemis, Zurich, 1950.

[6] Festschrift '75 Jahre chemischer Forschung an der Universität Zürich', produced by chemistry students of the University of Zurich, Zurich, 1909.

[7] Now the 'Seminar for Pedagogic Studies Zürichberg Section', Rämistrasse 59; in later years the 'Alte Kantonsschule' to differentiate from the new building on Rämistrasse 74.

[8] Löwig was honoured for his services to chemistry in Zurich on the occasion of the centenary celebration of the University of Zurich (1933) by the Zurich Chemical Society with a commemorative plaque in the entrance hall of the chemistry building on Rämistrasse 76.

[9] Later improved and expanded by Prof. Abeljanz, it was used in lecture courses up to the beginning of the 20th century.

[10] From 1911 the 'Eidgenössische Technische Hochschule' (ETH)

[11] The shared Chair for Chemistry was retained until 1872; for other subjects e.g. astronomy, geology, crystallography, mineralogy, palaeontology, pharmacology double professorships (ETH and University) still exist today.

[12] Owned by the Canton of Zurich until 1908; demolished when the Semper building was extended, $c a .1910$. 
[13] Pompejus Bolley, first professor for technical chemistry at the Polytechnic.

[14] A vibrant picture of the situation in chemistry at that time is given in: R. Meyer, 'Victor Meyer, Leben und Wirken eines deutschen Chemikers und Naturforschers 1848-1897', Akad. Verlagsges., Leipzig, 1917.

[15] Wislicenus earned his living as a teacher for chemistry and mineralogy at the Industrial School and from 1862 for chemistry at the Veterinary Medicine School (founded in 1820, first as a private institution and then as the staterun School for Veterinary Medicine; 1902 taken into the University as the Faculty of Veterinary Medicine).

[16] The real reasons for the abrupt departure of Wislicenus from Zurich are not easy to uncover. In 1861 Wislicenus had become a citizen of Zurich. His younger brother Hugo, senior lecturer for German language and history (1863-1866) and a teacher at the college in Küsnacht, died in an accident on the Tödi in 1866. The gradual transformation from a persecuted free-church member to a prominent German nationalist is clearly described in the obituary by Beckmann. ${ }^{[17]}$ During a celebration in Zurich of the victory of Germany over France, presided over by Wislicenus on 9.3.1871, a serious clash with demonstrators supporting France occurred which became known as the 'Concert Hall Riot'.

[17] E. Beckmann, Obituary for J. Wislicenus, Ber. Dtsch. Chem. Ges. 1904, 37, 4861.

[18] A. Werner and O. Meister wrote a vibrant account of the life of Merz filled with personal experiences: A. Werner, O. Meister, Verhand. Schweiz. Natur. Ges. 1904, $L X$.

[19] In 1877 the same matter was discussed again and Victor Meyer at the Polytechnic was asked to write an expert opinion. As the result of his recommendation, both professors were retained.

[20] Merz lived initially in the 'Kratz' in unusual lodgings. His peculiar, old-fashioned clothing gave him an odd appearance. But his generosity in financial matters and his helpfulness should be emphasised. He left the University a valuable legacy. Several books in the library of the Chemical Institutes originate from his extensive and well-ordered collection.

[21] Merz' style of writing in his publications is very dry. He presented the new results briefly and usually without any relation to an existing wider context.

[22] V. Meyer, Obituary for W. Weith, Ber. Dtsch. Chem. Ges. 1882, 15, 3291.

[23] M. Staub, 'Das chemische Laboratorium des Kantons Zürich 1877-1952', commemorative article for the 75th anniversary, Zurich, 1952.

[24] After the war in 1870/71 France lost Alsace to Germany. Werner was called up for military service on 1.10 .1885 . He still found the time to attend some lectures in chemistry at the technical university. His choice of Zurich for his studies later was probably due to the francophone tendencies of his family and the proximity to Mulhouse.

[25] The Polytechnic received the Ius Promovendi in 1909. Werner's dissertation was assessed by Abeljanz and Merz, who commented very positively on his work. His Klausurarbeit on 'The Theory of Aromatic Compounds' was judged as 'excellent'. Werner gained his doctorate at 23 with the words 'with particular merit for excellence'.

[26] Werner's portrait was probably painted at this time. It hung in the Director's office at Rämistrasse 76. Little is known about his work with Bertholot. It is possible that many of the experiments that Werne demonstrated in his lectures in inorganic chemistry originate from his time as a student in Paris. His successor Karrer used the same experiments unchanged for many years.

[27] See also [28, 29]. The appointment commission consisted of Profs A. Kleiner (physics, chairman), H. Abeljanz (chemistry), A. Heim (geology) and A. Lang (zoology). Based on the expert opinions of Prof. A. v. Baeyer, M. Berthelot, J. Wislicenus, Emil Fischer, V. Meyer, A. Hantsch and R. Gnehm, the following chemists were proposed as possible candidates: Prof. Hans v. Pechmann (Munich), Prof. F. K. J. Thiele (Munich) and Privatdozent Dr. A. Werner (Polytechnic). Werner was put on an equal par with the 13-years older v. Pechmann and before Thiele. The recommendations seem to be prophetic from today's viewpoint! A visit by Kleiner and Heim to one of Werner's lectures and a presentation to the Naturforschende Gesellschaft on 26.6.1893 impressed the Commission so much that they invited him to a formal lecture before the Faculty.

[28] P. Karrer, Obituary for A. Werner, Helv. Chim. Acta 1919, 3, 196; P. Karrer, Gesnerus (Zurich) 1966, 23, 273; P. Karrer, Helv. Chim. Acta Fasc. Extraord. 1967, 7.

[29] G. B. Kauffmann, 'Alfred Werner, Founder of Coordination Chemistry', Springer, Berlin, 1966.

[30] An unpleasant controversy developed over time with Abeljanz on this point that is given detailed treatment in the excellent biography by Kauffmann. [29] The situation damaged Werner's reputation internationally more than he deserved.

[31] Abeljanz' services to teaching should not be underestimated; as Staub commented:[23] "I had the honour as a young student to attend lectures by this excellent lecturer". Scientifically Abeljanz did not achieve much. It is odd that much later Karrer held the experimental lecture course in inorganic chemistry up to his retirement (1959) although a much better qualified lecture in Schwarzenbach was available in the same institute. A deal of the blame for this misfortune resulted from the unhappy connection of the professorial salary and the Kollegiengelder.
[32] Werner's private assistants had the job of verifying all the analyses of the doctoral students.

[33] e.g. A, Hantsch (SS 1885-1893), E. Bamberger (SS 1893-SS 1905), F. P. Treadwell (WS 1893/94-1918), G. Lunge (SS 1876-SS 1907), R. Gnehm (WS 1894/95-WS 1904/05), R. Willstätter (WS 1905/06-WS 1912/13), H. Staudinger (WS 1912/13-SS 1926).

[34] It should be remarked that most of Werner's $\mathrm{PhD}$ students came from abroad. Approx. 230 dissertations were completed under Werner's supervision. 46 students were Swiss (one woman), 179 were foreign (including 21 women); no nationality is given on some of the dissertations. In addition the entrance requirements for the University seemed to have been less strict that for the Polytechnic. Even today the ETH has the reputation as the 'Swiss' academic institution amongst high-school students. Karrer ${ }^{[28]}$ and Tiburtius ${ }^{[35]}$ give lively descriptions of the international character at the time of Werner.

[35] F. Tiburtius, 'Erinnerungen einer Achtzigjährigen', C. A. Schwetschke \& Sohn, Berlin, 1923.

[36] Offers came from an unknown university in 1895, the University of Bern 1897, the University of Vienna 1900, the University of Basel 1902, Eidgenössisches Polytechnikum 1905, the University of Würzburg 1910, the University of Leipzig 1911.

[37] Apparently Rämistrasse 59.

[38] After Chemistry moved out in summer and autumn 1978, the buildings Rämistrasse 74 and 76 were completely renovated; see Section 11.

[39] For the descriptions that were used for this Section see [6, 28, 29, 34, 40-44]. Kauffmann ${ }^{[29]}$ is particularly informative since many documents were used that were not accessible earlier.

[40] P. Pfeiffer, Obituary for Alfred Werner, Chemiker Zeitung 1913, 1517.

[41] E. Berl, 'Some Personal Recollections of Alfred Werner', J. Chem. Educ. 1942, 19, 153.

[42] I. Lifschitz, 'Alfred Werner', Z. Elektrochem. 1920, 26, 514.

[43] J. Read, 'Humour and Humanism in Chemistry', G. Bell \& Sons, London, 1947.

[44] D. H. Wilcox Jr., 'Werner and Dyes', Adv. Chem. Series 1966, 62, 86.

[45] The following text is based on refs [46-51].

[46] A. Werner, 'Lehrbuch der Stereochemie', Gustav Fischer, Jena, 1904.

[47] A. Werner, 'Neuere Anschauungen auf dem Gebiet der anorganischen Chemie', Vieweg \& Sohn, Braunschweig, 1920.

[48] G. Schwarzenbach, 'Alfred Werner and his Accomplishments', Helv. Chim. Acta, Fasc. Extraord. 1967, 38; G. Schwarzenbach, 'Die Entwicklung der Valenzlehre und Alfred Werner', Experientia 1966, 22, 633.

[49] F. Feigl, J. C. Bailar Jr., L. Horner, F. A. Cotton, C. Klixbüll Jörgensen, L. Malatesta, K. B. Yatsimirskii, D. H. 
Busch, A. D. Wadsley, articles in Helv. Chim. Acta, Fasc. Extraord. 1967.

[50] 'The Chemistry of the Coordination Compounds', Ed. J. C. Bailar Jr., Reinhold, N.Y., 1956 with 23 review articles from different authors.

[51] 'Werner Centennial', Ed. R. F. Gould, Adv. Chem. Series 62, Amer. Chem. Soc. 1967 with 42 review articles from different authors.

[52] G. N. Lewis, 'Valence and the Structure of Atoms and Molecules', The Chemical Catalog Co., N.Y., 1923.

[53] A. Hantzsch, A. Werner, Ber. Dtsch. Chem. Ges. 1890, 23, 11, 1243, 2336, 2764.

[54] Hantsch added the following postscript to the first article:[53] "In conclusion, the undersigned fulfils a duty of care for the case that the above developments should received some recognition, by giving the following declaration: the theory published here in collaboration with Herr A. Werner is the intellectual property of Herr Werner..."

[55] A. Werner, 'Beitrag zur Konstitution anorganische Verbindungen', Z. Anorg. Allg. Chem. 1893, 3, 267.

[56] An authentic description is given by King in ref. [44].

[57] Complexes prepared by Werner's doctoral students and coworkers are today part of the 'Werner Collection' in the archives of the Chemistry Institutes. There are thousands of individual substances.

[58] A. Werner, 'Über die Konstitution und Konfiguration von Verbindungen höherer Ordnung', Helv. Chim. Acta, Fasc. Extraord. 1967, 24.

[59] The diagnosis was 'progressive, degenerative, general arteriosclerosis, in particular of the brain'.

[60] The resistance of Werner to his condition and his belief in a full recovery that is obvious in every application for leave were based on good reasons: Werner always experienced periods of completely clear thinking. Witness to this is a letter dated 28.1.1918 to the Philosophical Faculty II in which he expresses his opinion thoroughly and far-sightedly over twelve pages on the subject of the successor to Prof. Pfeiffer. He must have suffered greatly when he finally realised the seriousness of his condition.

[61] See in this connection the description in ref. [74]

[62] The lecturers denoted with an asterisk had done their habilitations both at the University and ETH.

[63] The transcript of the Regierungsrat (meeting on 20.7.1916, RRB No. 1769) shows that the Erziehungsdirektion and the University Commission tried unsuccessfully to persuade Pfeiffer to change his mind.

[64] R. Wizinger wrote a short obituary for Pfeiffer: R. Wizinger, Helv. Chim. Acta 1953, 36, 2032

[65] P. Pfeiffer, 'Organische Molekülverbindungen', Enke, Stuttgart, 1922.

[66] Transcript of the Regierungsrat meeting of 28.2.1918, RRB No. 508

[67] Biographies of P. Karrer, see refs [68-70].
[68] C. H. Eugster, Vierteljahresschrift der Naturf. Ges. Zürich 1971, 116, 506; C. H. Eugster, Verhand. Schweiz. Naturf. Ges. 1971, 253; C. H. Eugster, Chemie in unserer Zeit 1972, 6, 147.

[69] A. Wettstein, Helv. Chim. Acta 1972, 55, 313.

[70] O. Isler, Biograph. Mem. Fellows Royal Soc. 1978, 24, 244.

[71] Karrer's brother Walter (19.8.1891-1961) obtained his doctorate in 1919 under the supervision of Profs Werner and Karrer on 'Optically Inactive and Active Diethylenediamine-Co-propionylacetonato Salts').

[72] Transcript of the Regierungsrat meeting of 16.10.1919, RRB No. 2748

[73] Unfortunately neither the names of the referees nor their recommendations could be found.

[74] The situation was not easy for Karrer in another aspect. From the records it is obvious that the Medical Faculty, during the procedure to appoint a successor to Werner and then again during the reappointment of the associate professorship previously awarded to Karrer and again during the appointment of the successor to Abeljanz, exerted strong pressure on the Philosophical Faculty II and the education authorities to be given a vote in the appointment and the design of the teaching and that they eventually applied for a Chair in Chemistry in the Medical Faculty (to the cost of a Chair in Phil Fac. II). Since they at the same time demanded an extensive reduction in the botany, zoology and comparable anatomy content, the Philosophical Faculty II stood firmly behind Karrer. The circumspect handling of the difficult discussions by the Erziehungsdirektor Dr. Mousson is the reason that chemistry was not forced into the role of a subsiduary subject.

[75] Karrer's character is described in $[65,68$, 69]. The not altogether happy relationship with Ruzicka in later years will not be described here.

[76] P. Karrer, Obituary for Prof. Ernst B. H Waser, Helv. Chim. Acta 1941, 24, 852.

[77] P. Karrer, Obituary for Carl Naegeli, Helv. Chim. Acta 1943, 26, 730 Vierteljahresschrift der Naturf. Ges. Zürich 1942, 87, 525.

[78] Further candidates under discussion were: Prof. Kaufmann, Geneva, Dr. Baragiola, Zurich, Dr. Ruggli, Basel, Dr. Gränacher, Dr. Waser, Dr. Ruzicka, all from Zurich.

[79] The archives contain letters from Profs P. A. Guye, Geneva and A. I. Bernoulli, Basel.

[80] Further opinions were probably obtained. The archives also contain an unfavourable reference from Albert Einstein, Berlin on Bernoulli (20.12.1919)

[81] Rooms in Rämistrasse 76; laboratory courses in Room 17, $\mathrm{PhD}$ students in rooms $9,12,14,15$.

[82] H. v. Halban, Obituary for Victor Henri, Vierteljahresschrift der Naturf. Ges. Zürich 1941, 86, 308.

[83] Obituary of Werner Kuhn and appreciation of his most significant and versatile research: H. Kuhn, Obituary for Werner Kuhn, Helv. Chim. Acta 1964, 47, 689.

[84] M. Kofler, Obituary for Hans v. Halban, Helv. Chim. Acta 1948, 31, 120.

[85] The full structure determination of the photoproducts of 'tetrabenzoyl-ethylene' was carried out much later, see ref. [86].

[86] J. R. Cannon, V. A. Patrick, C. L. Raston, A. H. White, Aust. J. Chem. 1978, 31, 1265.

[87] Obituary of K. Clusius and appreciation of his scientific work: K. Schleich, Helv. Chim. Acta 1964, 47, 234.

[88] G. Wagnière, Obituary for Heinrich Labhart, Helv. Chim Acta 1978, 61, 30.

[89] During the official inauguration ceremony, the building was characterised somewhat sarcastically as an 'academic shunt yard' by Regierungsrat president Dr. A. Gilgen.

[90] W. Schneider, Obituary for Gerold Schwarzenbach, Helv. Chim. Acta 1978, 61, 1949.

[91] Discovered by W. Biedermann, a coworker at that time of Schwarzenbach, after he had searched through the very large collection of organic dyes that still exists today, for suitable structures.

[92] In 1967 Schumacher was appointed professor at the University of Fribourg and since 1972 holds the Chair for Inorganic and Physical Chemistry at the University of Bern.

[93] H.-J. Hansen, M. Hesse, W. v. Philipsborn, Obituary for Hans Schmid, Helv. Chim. Acta 1978, 61, 1.

[94] Details associated with this appointment will not be stated here, for obvious reasons.

[95] See the detailed description in ref. [93].

[96] The assessment of the results of the Zurich research group by a competitor see: A. R. Battersby, H. F. Hodson, Quart. Rev. Chem. Soc. London 1960, 14, 77.

[97] When sufficiently large glass tubes for the chromatography columns could not be found, a tube made of stainless steel was obtained, bored and polished to give the exact calibre by a Zurich weapons factory.

[98] Karrer had long suspected that the calebasse alkaloids belonged to the strychnine class. In 1948 he proposed a chemical and pharmacological study of quaternary strychnine salts.

[99] The legislative planning work that preceded the partial relocation of the University cannot be described here for reasons of space, see ref. [100]. It is also not possible to describe the sometimes vehement agitation by influential student politicians against the Irchel project. But it should be emphasised that the Student Chemical Society expressed clear support for the project.

[100] 'Universität Zürich-Irchel, 1. Etappe', document from the Department of Public Buildings and the Department of Education of the Canton of Zurich, July, 1979.

[101] Transfer of room capacity from Chemistry to Zoology.

[102] Today this includes the following Institutes: Inorganic, Organic, Physical Chemistry, Zoology, Zoological Museum (scientific part), IT (user centre), and facility management. All first year students in the sciences and medicine 
attend lectures, tutorials and practical courses in these buildings.

[103] P. Karrer, 'Zürich als Stätte chemischer Forschung in den letzten 100 Jahren', in 'Festschrift zur 200-Jahr-Feier der Naturforschenden Gesellschaft in Zurich', 1946, p. 178.

[104] It is not possible to give exact figures because in the early years many external dissertations (e.g. from the Polytechnic until 1909) were submitted to the University for a doctorate. When the external place of research is obvious from the dissertations, they were not included in our records. However, those dissertations that were prepared at the University but the doctorate awarded elsewhere are also not counted.
[105] The large number of diploma theses are not discussed here, although many exceed the range of many earlier dissertations because the diploma students, with a few. exceptions, went on to start a dissertation

[106] In the travelling exhibition that the University made to celebrate its 150th anniversary, the Chemistry Institutes produced a slide show of the many and diverse professions that the former doctorates of chemistry have moved into.

[107] The senior lecturers and the titular professors H. Streuli and K. Bernauer are employed in industry and do not have research groups at the Institute of Organic Chemistry. 